NBER WORKING PAPER SERIES

\title{
MISFORTUNE AND MISTAKE: \\ THE FINANCIAL CONDITIONS AND DECISION-MAKING ABILITY OF HIGH-COST LOAN BORROWERS
}

\author{
Leandro Carvalho \\ Arna Olafsson \\ Dan Silverman \\ Working Paper 26328 \\ http://www.nber.org/papers/w26328
NATIONAL BUREAU OF ECONOMIC RESEARCH
1050 Massachusetts Avenue
Cambridge, MA 02138 \\ September 2019, Revised November 2020
}

This research is carried out in cooperation with Meniga, a financial aggregation software and smartphone application provider. We are grateful to the executives and employees who have made this research possible. We thank Christine Dobridge, John Gathergood, Nicola Persico, and participants in several seminars and conferences for their many helpful comments on the paper. Special thanks to Jon Zinman for his detailed and insightful comments on an earlier draft. The views expressed herein are those of the authors and do not necessarily reflect the views of the National Bureau of Economic Research.

At least one co-author has disclosed additional relationships of potential relevance for this research. Further information is available online at http://www.nber.org/papers/w26328.ack

NBER working papers are circulated for discussion and comment purposes. They have not been peer-reviewed or been subject to the review by the NBER Board of Directors that accompanies official NBER publications.

(C) 2019 by Leandro Carvalho, Arna Olafsson, and Dan Silverman. All rights reserved. Short sections of text, not to exceed two paragraphs, may be quoted without explicit permission provided that full credit, including (C) notice, is given to the source. 
Misfortune and Mistake: The Financial Conditions and Decision-making Ability of High-cost Loan Borrowers

Leandro Carvalho, Arna Olafsson, and Dan Silverman

NBER Working Paper No. 26328

September 2019, Revised November 2020

JEL No. D14,G2

\section{ABSTRACT}

The appropriateness of many high-cost loan regulations depends on whether demand is driven by financial conditions ("misfortunes") or imperfect decisions ("mistakes"). Bank records from Iceland show borrowers have especially low liquidity just before getting a loan, but their spending is not especially low in the days before the loan arrives and some spend a substantial fraction of the loans on seemingly inessential items. Borrowers exhibit lower decision-making ability (DMA) in linked choice experiments: 45\% of loan dollars go to the bottom $20 \%$ of the DMA distribution. Standard determinants of demand do not explain this relationship, which is also mirrored by the relationship between DMA and an unambiguous "mistake." Both "misfortune" and "mistake" thus appear to drive demand.

Leandro Carvalho

Center for Economic and Social Research

University of Southern California

635 Downey Way

Los Angeles, CA 90089

leandro.carvalho@usc.edu

Arna Olafsson

Copenhagen Business School

Department of Finance

Solbjerg Plads 3

2000 Frederiksberg

Denmark

ao.fi@cbs.dk
Dan Silverman

Department of Economics

W.P. Carey School of Business

Arizona State University

P.O. Box 879801

Tempe, AZ 85287-9801

and NBER

Daniel.Silverman.1@asu.edu 


\section{Introduction}

Several forms of consumer credit, including payday loans, deposit advance products, and vehicle title loans, are controversial because they are used disproportionately by low-income households and involve high fees. In 2015, lower-income U.S. households spent an estimated $\$ 62.7$ billion in interest and fees on short-term loan products like these (Schmall and Wolkowitz, 2016). Critics call the loans usurious and warn that they take advantage of financially unsophisticated borrowers who end up in harmful cycles of debt. Proponents describe the high costs of the loans as necessary given the risk to the lender, and note that the harm to the borrower of foregoing other obligations or opportunities can be much greater. They argue that these forms of credit provide valuable liquidity to those who struggle to find it elsewhere.

The controversy surrounding high-cost credit has spurred both regulation aimed at protecting unsophisticated borrowers, and concern about that regulation. ${ }^{1}$ The costs and benefits of this regulation depend on the extent to which demand for high-cost credit is due to "misfortune" and "mistake." By "misfortune" we mean adverse financial conditions that cause borrowers to place high value on a loan but also limit its availability at low cost. These circumstances include income, liquidity, and expenditure shocks. By "mistake" we mean an imperfect choice. A choice that, given the same information, the person would make differently if he attended to it more carefully or had greater ability to assess the factors that determine its payoff. ${ }^{2}$ If borrowers turn to high-cost credit because of "misfortune," policy is justified if it reduces market imperfections that limit trade in credit. If borrowers use high-cost credit because they do not properly balance its costs and benefits, policy should also work to protect consumers from this harm.

This paper links rich administrative data with information from surveys and experiments, all at the individual level, to assess the influence of "misfortune" and "mistake" in determining the

\footnotetext{
${ }^{1}$ Several U.S. States have, for example, prohibited payday loans, placed restrictive caps on the implied interest rates, or instituted "cooling off periods" to preclude rolling over payday debt (Bhutta, Goldin, and Homonoff, 2016). At the Federal level, in 2017 the U.S. Consumer Finance Protection Bureau approved rules mandating that lenders underwrite loans to ensure the borrower can pay back while meeting basic needs, and limiting the number of times lenders can attempt unsuccessfully to withdraw loan payments from a borrower's bank account. The implementation of those rules has since been placed on hold as opponents raise concerns that the regulations impose important burdens on lenders and will reduce the availability of valuable credit.

${ }^{2}$ This concept of a choice imperfection relates to Gilboa's (2012) definition of rational behavior. In this view, a person's choices are irrational or, in our words, imperfect if he or she thinks of them erroneous after careful explanation, analysis, and consideration of their costs and benefits.
} 
demand for high-cost credit. Evaluating the role of "mistakes" is especially challenging because imperfect choices are hard to identify. On the one hand, unobserved constraints, preferences, or beliefs can justify many behaviors as optimal, and caution dictates respect for consumer choice. On the other hand, evidence points to the potential for "mistakes." Prior studies show the choice to use a payday loan is sometimes ill-informed (Bertrand and Morse, 2011), may be dominated by cheaper forms of credit (Agarwal et al. 2009), and is often followed by undesirable consequences (Melzer 2011, 2018; Carrell and Zinman, 2014; Gathergood et al. 2018).

In this paper, we address this identification problem in two complementary ways. First, using daily records drawn from individual bank and credit card balances and transactions in Iceland, we describe the (changing) financial conditions and behaviors associated with payday loan demand. These administrative data are derived from a financial aggregation app, serving approximately 20 percent of the Icelandic adult population, that links records from its users' various financial accounts. In that analysis, we document the extent to which the individual circumstances of payday borrowers differ from that of others in the data, how those circumstances change in the days leading up to and following the receipt of a payday loan, and how spending changes upon receipt of the loan.

Second, using the results of experiments conducted via online survey with 1,700 users of the financial aggregator, we capture measures of both economic preferences and decision-making ability (DMA). The experiments involve multiple incentivized choices under risk and uncertainty and about the intertemporal allocation of money. The price variation in these experiments is sufficiently rich to permit well-powered tests of consistency with utility maximization and related, normative properties of choice.

Following Choi et al. (2014) and Carvalho and Silverman (2019), we interpret consistency with these normative properties of choice as a measure of financial DMA. In the context of the experiments, consistency with utility maximization means the participant reveals a single, stable, and sensible objective of the several financial choices he makes while facing varying incentives over a short period of time (Afriat, 1967). We interpret revealing such an objective as reflecting an ability to attend adequately to financial decisions, understand their relevant tradeoffs, and map available choices into objectives. This interpretation is supported by evidence in studies showing 
these measures are positively correlated with financial success in both experiments and in the field. See Choi et al. (2014), Stango and Zinman (2019), Carvalho and Silverman (2019).

The results from the administrative data alone show that most payday borrowers have only limited access to other forms of liquidity, and are on average especially illiquid on the day they take the loan. Over the nearly 6 years of observation, payday borrowers maintain, on average, essentially no liquid assets, and carry an average of about a month's salary in debt in the form of overdrafts on their checking accounts. Looking back over the 30 days prior to getting a loan, the average of a borrower's checking and savings balances, net of credit card balances, declines steadily until the day the loan arrives and then slowly recovers over the next three weeks to levels close to the levels 30 days prior to the loan. From that point on, liquidity starts declining again.

Some prior research has studied the extent to which payday loan demand is attributable to "mistake" by testing whether borrowers have access to cheaper credit at the time they take the payday loan. Results have been mixed, with some finding large fractions of payday borrowers with access to substantial amounts of credit at lower cost (Agarwal et al., 2009) and others finding that the bulk of payday borrowers have virtually no other cheaper form of market credit available when they take the loan (Bhutta et al., 2015).

In the Icelandic data, which integrate available credit from multiple sources, a majority of payday borrowers have little if any cheaper credit available through market sources at the time they take the loan. When she takes out the loan, the median borrower has access to cheaper credit in an amount equivalent to 5 days of her average spending. There is, however, substantial heterogeneity and $25 \%$ of payday loan borrowers have, on the day they receive their loan, access to cheaper credit amounting to more than 3 weeks of average spending.

The administrative data also indicate that part of the loans is spent on inessential items. Average spending on alcohol, meals out, entertainment, lotteries, and gambling more than doubles on the day the loan arrives, though it remains a modest fraction of the average loan.

Taken together, the evidence from the administrative data suggests a substantial but not a dominant role for "mistake" in driving demand for payday loans. On their own, however, the administrative data results are not dispositive and may be conservative in identifying "mistakes." Even among those without access to cheaper credit, the choice to take a payday loan may not be 
best. To further examine the role of "mistake" in the demand for high-cost loans, we therefore relate DMA as measured in the experiments to demand for payday loans.

Payday loan borrowers exhibit substantially lower DMA in the experiments and those with low ability play an outsized role in the market for payday loans. In these data, $29 \%$ of payday loan dollars are lent to the bottom $10 \%$ of the DMA distribution, and $45 \%$ are lent to the bottom $20 \%$ of the distribution. In individual-level regression analysis, the relationship between DMA and high-cost loan demand is not explained by demographic characteristics, granular information on economic circumstances, or measures of preferences from the experiment.

The negative conditional correlation between DMA measures and high-cost loan demand is consistent with the hypothesis that "mistakes" are quantitatively important drivers of demand for these loans. Such inference would be misguided, however, if these measures of DMA were simply capturing a "type" of consumer whose unmeasured constraints, preferences, or beliefs rationalize demand for high-cost loans. ${ }^{3}$ To further evaluate this possibility, we study the relationship between measures of DMA from the experiment and an unambiguous "mistake" in the administrative data. The "mistake" is the accrual of non-sufficient funds (NSF) fees. These fees obtain when, in the process of using a debit card to make a purchase, an individual exceeds his or her checking account overdraft limit. Different from costly overdrafts in markets like the U.S., there is no benefit to exceeding the limit because the purchase will not be authorized. In this way, a choice that results in an NSF fee appears clearly imperfect; it is dominated by the decision not to try to make the purchase. NSF fees can thus provide further evidence on the validity of using experimental measures of consistency with (normatively appealing) utility maximization as measures of DMA.

The results on NSF fees are qualitatively similar to those for high-cost loan demand. Conditional on demographic characteristics, economic preferences, and financial conditions, those with lower DMA incur significantly more NSF fees. These results are consistent with the hypothesis that DMA, as captured in the experiments, measures a set of skills useful for avoiding financial mistakes in field settings. This evidence bolsters the view that high-cost credit is, holding

\footnotetext{
${ }^{3}$ This distinction is blurred if some of those constraints are, themselves, produced by prior "mistakes." An obvious example is the level of liquidity that results from having taken out a payday loan in the past. If an earlier decision to take a payday loan was a "mistake" an individual's current level of liquidity, treated as a constraint in our analysis, would in fact be a consequence of an earlier "mistake."
} 
financial circumstances fixed, disproportionately taken up by those who struggle to make financial decisions that are consistent with their objectives. To our knowledge, this is the first study to provide evidence that DMA is related to the uses of controversial forms of consumer credit. More generally, it is first to use administrative bank records to study the relationship between measures of consistency with (normatively-appealing) utility maximization and field behaviors and outcomes.

Last, we evaluate the external relevance of the Iceland findings and the potential for relying on survey data alone to do similar analyses, by comparing, to the extent possible, the relationships estimated there with those estimated from a survey of U.S. consumers. The U.S. survey data on economic outcomes are self-reported and the measures of high-cost credit take-up, preferences, and DMA, are relatively coarse. Nevertheless, we find that the relationship between DMA and the probability of receiving a payday loan is very similar in these U.S. data and in the Icelandic data.

The linked administrative and experimental measures from Iceland, augmented by U.S. survey data, thus indicate that both "misfortune" and "mistake" are important for high-cost loan demand. Our analysis does not provide a quantitative assessment of the net welfare consequences of this form of credit. It does not describe optimal policy as function of the estimated relationship between payday loan demand and either liquidity or DMA. Instead, these results provide evidence that interventions aimed at consumer protection in these markets is justified. The findings indicate that policy should be concerned both with the possibility that market imperfections limit trade and, at the same time, that "mistakes" lead to excess trade in these kinds of loans.

\section{Related Literature}

This paper contributes to a literature on high-cost credit, the financial conditions of borrowers in those markets, and the consequences of access to these loans. Prominent examples from that literature include Agarwal et al. (2009), Zinman (2010), Melzer (2011, 2018), Morse (2011), Bertrand and Morse (2011), Bhutta et al. (2015), Bhutta et al. (2016), Gathergood et al. (2018), and Skiba and Tobacman $(2018 \mathrm{a}, \mathrm{b})$. Our paper is distinguished from the bulk of that literature by its use of comprehensive, high-frequency, administrative data on the balances and transactions of the study sample that reveal the liquidity and spending patterns of loan recipients. Prior studies with access to administrative data have used credit files to observe debt and the availability of other sources of credit, but not the entire balance sheet of the consumer over time. For similar reasons, these prior 
studies could not examine patterns of spending out of payday loans. ${ }^{4}$ In this way, we obtain a granular view of the financial circumstances of high-cost credit borrowers and novel insight into how they spend the loans. Our analysis of the administrative data thus provides new evidence on the importance of "misfortune" in driving demand for these loans.

Like our paper, Alcott et al. (2020) evaluates whether decisions to take high-cost loans are imperfect and whether consumer protection in that market is thereby justified. Their paper conducts an innovative experiment to elicit both the beliefs of payday loan borrowers about the likelihood of future borrowing, and their willingness to pay for a $\$ 100$ incentive to avoid future borrowing. The responses in these experiments are then linked to administrative records on payday loan borrowing and used to estimate the structural parameters of a model and conduct welfare analysis. In their model, imperfect choice is identified with time-inconsistent preferences or mistaken beliefs about those preferences and the future take-up of loans. Our approach integrates more information about the borrower's balance sheet and puts less structure on the mechanisms behind imperfect choice. In this way we can accommodate more sources of choice imperfection but cannot make the quantitative welfare assessments that Alcott et al. (2020) can.

Our reliance on administrative records from a financial aggregator relates to a growing literature that uses these kinds of data to study a variety of phenomena. Examples include Gelman et al. (2014, 2018), Kueng (2018), and Baker (2018). In particular, these Icelandic data have been used to study the dynamics of liquid asset holdings and spending in response to income (Olafsson and Pagel, 2018), how different generations use financial products to manage their finances (Carlin, Olafsson, and Pagel, 2019), and how consumers use credit lines in response to transitory income shocks (Hundtofte, Olafsson, and Pagel, 2019).

Our interest in measuring consistency with utility maximization, and relating it to observable characteristics and behavior, connects our work to the literature that has developed different measures of economic rationality (Dean and Martin, 2016; Halevy et al. 2018; Polisson et al. 2019; Echenique et al. 2019) and a literature that has used such measures to study the correlates and determinants of rationality (Carvalho and Silverman, 2019; Banks et al. 2019; Kim et al. 2018). Our

\footnotetext{
${ }^{4}$ Dobridge (2016) uses the Consumer Expenditure Survey to measure the relationship between spending responses to shocks and access to payday loans. That paper does not observe the take-up of loans and thus cannot evaluate directly how they are spent.
} 
analysis draws on elements of this literature in its use of recent advances in revealed preference tests of (the degree of) consistency with different axioms of choice. It is also, to the best of our knowledge, the first to use administrative bank records to relate measures of consistency with (normativelyappealing) utility maximization to field behaviors and outcomes.

A link between experiments and comprehensive administrative records is rare in the broad stream of research that seeks to understand the fundamentals of economic behavior through financial data. To our knowledge, the closest analogue is Epper et al. (2018), which links experiments to yearly snapshots of assets and liabilities, and no other study has linked experimental economic data to comprehensive and high-frequency bank data at the individual level. As important, our analysis allows not only for heterogeneity in (non-standard) economic preferences, but also considers the importance that violations of utility maximization may have in understanding financial decisions (Choi et al. 2014; Stango and Zinman, 2019).

\section{Background - Consumer Credit in Iceland}

In many countries, credit cards are a leading source of revolving credit to consumers. In Iceland, however, overdrafts on checking accounts are the most common form of revolving consumer debt. Virtually all checking accounts in Iceland offer an overdraft facility, the size of which is based on credit history, income, and assets. Overdrafts can be made at any time without consulting the bank and overdraft status can be maintained indefinitely (subject to ad hoc reviews). Overdrafts dominate the unsecured consumer credit market, representing approximately $10 \%$ of all household loans during 2011-2017, and they charge average annual percentage rates (APRs) of around $12 \% .^{5}$

While overdraft facilities on checking accounts are the primary source of revolving credit in Iceland, access to high-cost, short-term loans has grown substantially in recent years. Payday loans were first offered in Iceland in 2009. They require only a minimal credit assessment, are for short terms, and are available almost immediately after application in potentially substantial amounts. To obtain a loan, individuals need to (i) affirm their legal competence to manage their financial affairs, (ii) provide the Icelandic equivalent of the Social Security Number, (iii) be

\footnotetext{
${ }^{5}$ Statistics, Central Bank of Iceland www.sedlabanki.is/library/Fylgiskjol/Hagtolur/Fjarmalafyrirtaeki/2019/1013\20INN_Utlan_052019.xlsx
} 
formally registered as living in Iceland, (iv) supply an active email address/phone number and an active debit card number, and (v) not be undergoing debt mitigation. While they are called "payday loans," obtaining this form of credit in Iceland requires no documentation of employment or the timing of paydays. Lending periods are flexible; individuals can choose durations between 1 and 90 days. Payday lenders operate only online or through short message services (SMS). Upon successful application, loans are deposited in the borrower's bank account within a few minutes. The total borrowing limit of the five providers active during the period covered by our sample was approximately $\$ 6,000$.

Oversight of Iceland's payday loan market is weak. For regulatory purposes, payday lenders are not classified as financial institutions, they do not need an operating license, they are all headquartered abroad, and government supervision of their activities is limited. Indeed, payday lending was effectively unregulated in Iceland prior to 2013.

Due in part to the lack of government oversight, systematic evidence about the costs of payday loans in Iceland is limited. Kristjánsdóttir (2013) documents the costs of payday loans by all the Icelandic payday providers in 2013 and compares the costs of payday loans to those in other Nordic countries and the UK. This comparison shows that in 2013 the APR of payday loans was higher in Iceland than in the other countries, with APRs starting at approximately 2,800\%.

In November 2013, Iceland's Consumer Loans Act no. 33/2013, capped the APR on consumer debt at 50 percentage points above the Central Bank of Iceland's key interest rate. There is no evidence, however, that this regulation was binding on the costs of payday loans. Payday lenders appear to have circumvented or ignored the regulation. Some lenders skirted the law by, for example, having borrowers purchase e-books in exchange for expedited loan processing. Such fees are not included in the calculation of the APR. Others either ignored the law or interpreted their fees as exempt from it. To illustrate, Figure A1 in the Appendix shows an example of a payday loan contract and a screenshot from the homepage of one of the payday loan providers. These examples were collected by Iceland's Ministry of Tourism, Industry, and Innovation in 2018. The figure shows that the APR charged on a 30-day loan was 3,448.8\%, very similar to the APRs documented by Kristjánsdóttir (2013) prior to the act. Consistent with the view that the regulation was not binding for payday lenders, we find no evidence in the administrative data of a discontinuous change in the number or size of loans around November 2013. 
Information on the size of the payday lending market in Iceland is limited. To the best of our knowledge, ours is the first study to compare the use of payday loans to the use of other sources of consumer credit and relate it to other financial behavior in Iceland. Approximately $5.6 \%$ of the consumers in our data used payday loans at least once during a period of 6 years. Thus, as in other developed economies, payday borrowing is relatively uncommon; but the magnitude of borrowing among those who use payday loans users is substantial and seems likely to have an important influence on their financial circumstances. ${ }^{6}$

\section{Administrative Data}

We use data from Iceland gathered by Meniga, a financial aggregation software provider to European banks and financial institutions. Its account aggregation platform allows bank customers to view and manage all their bank accounts and credit cards across multiple banks in one place. Each day, the software automatically records all the bank and credit card transactions, including descriptions, balances of credit cards, checking accounts, and savings accounts, as well as overdraft and credit card limits. Additionally, the data contain demographic information, such as age and gender.

Anyone who has an online bank account in Iceland can register at meniga.is to access the personal financial management platform. Furthermore, all larger banks in Iceland allow their customers to sign up directly through their internet bank. All who sign up agree to be a part of a sample for analytical purposes. In January 2017, the Icelandic population was 338,349 individuals, of whom 262,846 were older than 16. At the same time, Meniga had 50,573 users, which is about 20 percent of that population. Because their service is marketed through banks, the sample of users is fairly representative-see Table 4 in section $\mathrm{V}$.

We restrict our analysis sample to users for whom we observe income and demographic information and whose expenditure data is credible. ${ }^{7}$ In our analysis, we use 5 different types of

\footnotetext{
${ }^{6}$ This is consistent with statistics from the Debtors' Ombudsman of Iceland for debt mitigation which shows that the share of people aged 18-29 who have applied for debt relief has increased sharply in recent years, and payday loans account for a much larger proportion of these troubled borrowers' total obligations. By 2017, 70\% of debt mitigation applicants aged 18-29 owed payday loans. Among applicants who had payday debt, it accounted for about $20 \%$ of their total debt (Central Bank of Iceland, 2018).

${ }^{7}$ The credibility of expenditure data depends on how well-integrated a user is with Meniga. When a user signs up, he agrees to import two years of transaction history into the Meniga database. If a user does not import all of his accounts
} 
information from the administrative data. First, we use the amounts and dates of payday loans. Second, we use the daily balances of checking accounts, savings accounts, and credit cards, and overdraft and credit card limits. Third, we use transaction-level information on income receipts, including the date of receipt and the income source, which we use to calculate monthly salary and monthly income. Fourth, we use information on the number of non-sufficient funds charges each month. Finally, we use transaction-level information on spending, including the type of expenditure (e.g., transportation vs. groceries). The different pieces of information are available for different periods. Data on payday loans are available from January 1, 2011 to January 31, 2017. Information on daily balances is available from September 1, 2014 to February 13, 2017. Income is available from January 6, 2011 to February 19, 2017, expenditures from January 1, 2011 to March 2, 2017, and non-sufficient funds charges from January 2011 to February 2017 (these are reported on a monthly basis).

After applying the filters, we have data for 12,747 Meniga users, of whom 717 have taken at least one payday loan during the 6 years of observation.

\section{Preliminary Statistics}

Table 1 shows summary statistics of the Meniga sample regarding payday loans. All monetary figures shown in the paper are in hundreds of Icelandic króna (kr.). In 2017, 100 kr. corresponded approximately to 1 US dollar. Therefore, the reader can treat the monetary figures as US dollars. Restricting attention to loans of $\$ 10$ or more, the mean and the median of loans are approximately \$250 and \$200. During the 6-year period of the data, payday loan borrowers took an average of 20 loans. The median borrower took 10 loans and borrowed \$2,240.

in use, his financial activity will reflect that. We can therefore detect if accounts in use are not linked by imposing a minimum data activity criterion that is captured by the following requirements: (1) The user must be active for at least 23 out of 24 months; (2) have been active for the past 3 months; and (3) have at least 5 transactions in food (groceries or eat out). After applying these filters, comparison with the Statistics Iceland's consumption index and with credit card transactions indicates that the spending captured by the platform is comparable to those in other sources. 
Table 1: Summary Statistics of Payday Loans

\begin{tabular}{rcccccc}
\hline & & \multicolumn{5}{c}{ Percentiles } \\
\cline { 2 - 7 } & Mean & 10 th & 25th & 50 th & 75 th & 90 th \\
\cline { 2 - 7 } Amount Individual Loans & 249 & 100 & 130 & 200 & 300 & 400 \\
& & & & & & \\
Among Payday Loan Borrowers & & 1 & 3 & 10 & 26 & 50 \\
Number of Payday Loans & 20 & 200 & 600 & 2,240 & 5,650 & 12,780 \\
Total Amount Borrowed & 4,876 & & &
\end{tabular}

Note: This table shows summary statistics for 12,556 individual payday loans taken by 641 borrowers. The sample is restricted to loans of $\$ 10$ or more.

Table 2 compares payday loan borrowers to non-borrowers. Borrowers earn less and have less money in their checking and savings accounts. Some borrowers have relatively high incomes, however. The 90th percentile of the distribution of monthly income after taxes is approximately

Table 2: Summary Statistics of Income, Checking, Savings, and Credit Cards

\begin{tabular}{|c|c|c|c|c|c|c|}
\hline & \multirow[b]{2}{*}{ Mean } & \multicolumn{5}{|c|}{ Percentiles } \\
\hline & & 10th & 25th & 50th & 75th & 90th \\
\hline \multicolumn{7}{|l|}{ Monthly Salary } \\
\hline Non-Borrowers & 5,013 & 853 & 1,652 & 2,973 & 4,627 & 6,718 \\
\hline Borrowers & 2,378 & 855 & 1,332 & 2,133 & 3,012 & 4,091 \\
\hline \multicolumn{7}{|l|}{ Monthly Income } \\
\hline Non-Borrowers & 5,931 & 1,295 & 2,219 & 3,635 & 5,386 & 7,654 \\
\hline Borrowers & 3,074 & 1,315 & 1,919 & 2,799 & 3,872 & 5,092 \\
\hline \multicolumn{7}{|l|}{ Checking Balance } \\
\hline Non-Borrowers & -226 & $-6,246$ & $-1,662$ & 187 & 1,233 & 3,618 \\
\hline Borrowers & $-3,121$ & $-8,867$ & $-5,087$ & $-1,291$ & 29 & 334 \\
\hline \multicolumn{7}{|l|}{ Savings Balance } \\
\hline Non-Borrowers & 3,744 & 0 & 0 & 3 & 929 & 7,250 \\
\hline Borrowers & 456 & 0 & 0 & 0 & 21 & 617 \\
\hline \multicolumn{7}{|l|}{ Credit Card Balance } \\
\hline Non-Borrowers & 1,531 & 0 & 168 & 1,147 & 2,267 & 3,540 \\
\hline Borrowers & 748 & 0 & 0 & 0 & 971 & 2,262 \\
\hline
\end{tabular}


to the individual's average monthly salary and average monthly income between February 2011 and January 2017. The balances correspond to the individual's median daily balances between September 1, 2014 and February 13, 2017.

$\$ 5,000$. The typical borrower has no money in her savings account and is overdrafted by $\$ 1,291$. Borrowers also have lower credit card balances, which partly reflects that they have lower credit card limits (not shown in the table).

\section{Patterns of Liquidity}

Most payday borrowers have little liquidity, and Figure 1 shows that, on average, they are more illiquid in the days leading up to getting the loan. The figure shows the average liquidity i.e., the sum of savings and checking account balances, overdraft limit, and credit card limit minus balance - as a fraction of the long-run, individual-level average of daily spending, before and after the loan was taken. Liquidity gradually declines by an average of about 3 days of spending until the day the loan is taken. Liquidity then temporarily bounces back to the original level. After the recovery, liquidity starts falling again.

Figure 1: Patterns in Liquidity Around Payday Loans

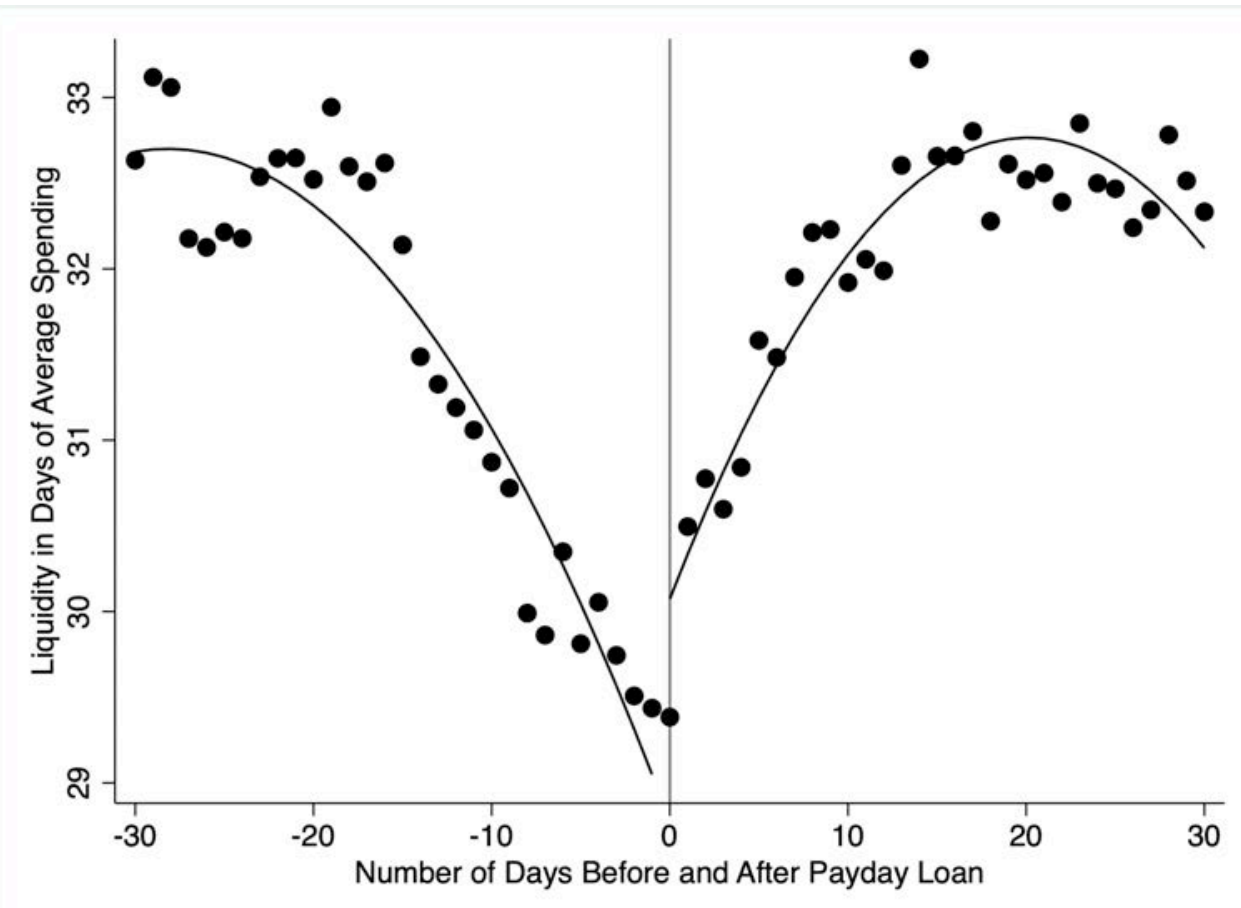


Note: This figure shows a time event study of liquidity in days of average spending 30 days before and 30 days after a payday loan was taken. The analysis adjusts for when the interval between two loans is shorter than 30 days. It also includes day-of-the-week and calendar-day-of-the-month effects (see Appendix). The curves show pre-loan and post-loan quadratic trends. The analysis uses data on payday loans taken between October 1, 2014 and January 14, 2017 because the data on checking, savings, and credit card accounts is available for the period between September 1, 2014 and February 13, 2017. 3,453 payday loans were taken between October 1, 2014 and January 14, 2017 by 311 participants.

Focussing on just the day before the loan is taken, Table 3 shows that many payday borrowers have no access to cheaper liquidity when they take loans. ${ }^{8}$ At the median, even if a payday borrower reaches her overdraft limit, withdraws all her savings, and maxes out her credit cards, she can draw just 5 days of spending. There is, however, substantial heterogeneity. Some payday borrowers have cheaper alternatives. In particular, those in the $75^{\text {th }}$ and $90^{\text {th }}$ percentiles have about 8 and 30 average days of spending, respectively, available to them if they borrow via overdraft and tap into their savings. If we include what is possible to borrow on credit cards, this upper part of the distribution can borrow at least 3 weeks worth of average spending at lower interest rates. This segment of the borrowing population appears to be making imperfect decisions in using credit that is more expensive than necessary.

Table 3: Liquidity One Day Before Taking Payday Loan

\begin{tabular}{rcccccc}
\hline & & \multicolumn{5}{c}{ Percentiles } \\
\cline { 2 - 7 } & Mean & 10th & 25th & 50 th & 75th & 90th \\
\cline { 2 - 7 } Checking Balance + Overdraft Limit (1) & 5 & 0 & 0 & 1 & 4 & 13 \\
Savings Balance (2) & 11 & 0 & 0 & 0 & 0 & 10 \\
Credit Card Limit - Credit Card Bal. (3) & 10 & 0 & 0 & 0 & 7 & 29 \\
$(1)+(2)$ & 16 & 0 & 0 & 1 & 8 & 30 \\
$(1)+(2)+(3)$ & 26 & 0 & 1 & 5 & 23 & 61
\end{tabular}

Note: This table shows summary statistics of daily balances as a fraction of average daily spending borrowers had one day before they took payday loans. The number of payday borrowers is 322 and the number of loans is 3,672 .

\section{Spending Around Payday Loans}

The preceding results on liquidity show that many, but not all, high-cost loan borrowers have limited options for cheaper liquidity when they take a payday loan. A related and important

\footnotetext{
${ }^{8}$ Figure 1 and Table 3 provide slightly different estimates of the average liquidity one day before the loan is taken because the former adjusts for when the interval between two loans is shorter than 30 days and nets out day-of-theweek and calendar-day-of-the-month effects.
} 
justification for high-cost loans is that they can be used to cover essential expenditures, like food, housing, medicine, or transportation to work for those with no better options for liquidity. These kinds of expenditure may be costly to postpone or forgo, and may thus justify a high-cost loan.

Inessential expenditure is difficult to identify in these bank records because most categories of spending could include both urgent and non-urgent elements. We are, however, able to distinguish from all other categories spending on alcohol, food and drink outside the home, recreation, lotteries, or gambling. ${ }^{9}$ (Addiction or other conditions may make alcohol and gambling essential to the household, but these forms of expenditure are not mentioned in policy debates as justifications for high-cost loans.) Figure 2 estimates the patterns of these seemingly inessential forms of spending (top panel) and of all other spending (bottom panel) around the arrival of a payday loan. The analysis conditions on day-of-week and day-of-month effects and excludes loans that are taken within 31 days of another loan to avoid the confounding effect of rollovers which produce a very small net change in liquidity.

Figure 2 shows only a modest decline in spending in the days leading up to the payday loan. In particular, there is no evidence in these spending data of financial crisis or special deprivation in the time leading up to the loan. In each of the 30 days prior to taking the loan, borrowers spend, on average, about $95 \%$ of their long-run average spending per day. In the 2 days just before the loan is taken, spending is somewhat lower - borrowers spend on average $80 \%$ of their long-run mean spending per day.

The figure also shows spikes in spending on the seemingly inessential forms of consumption and in other expenditures. The estimated spikes indicate that both inessential spending and other spending more than double on the day the loan arrives. These data thus provide evidence that at least a small fraction of payday loan dollars are used to fund forms of consumption that could likely be postponed or foregone at low cost.

\footnotetext{
${ }^{9}$ The expenditure data do not have information on non-discretionary expenditures such as utility charges, mortgage payments, and real estate taxes.
} 
Figure 2: Spending Around Payday Loans
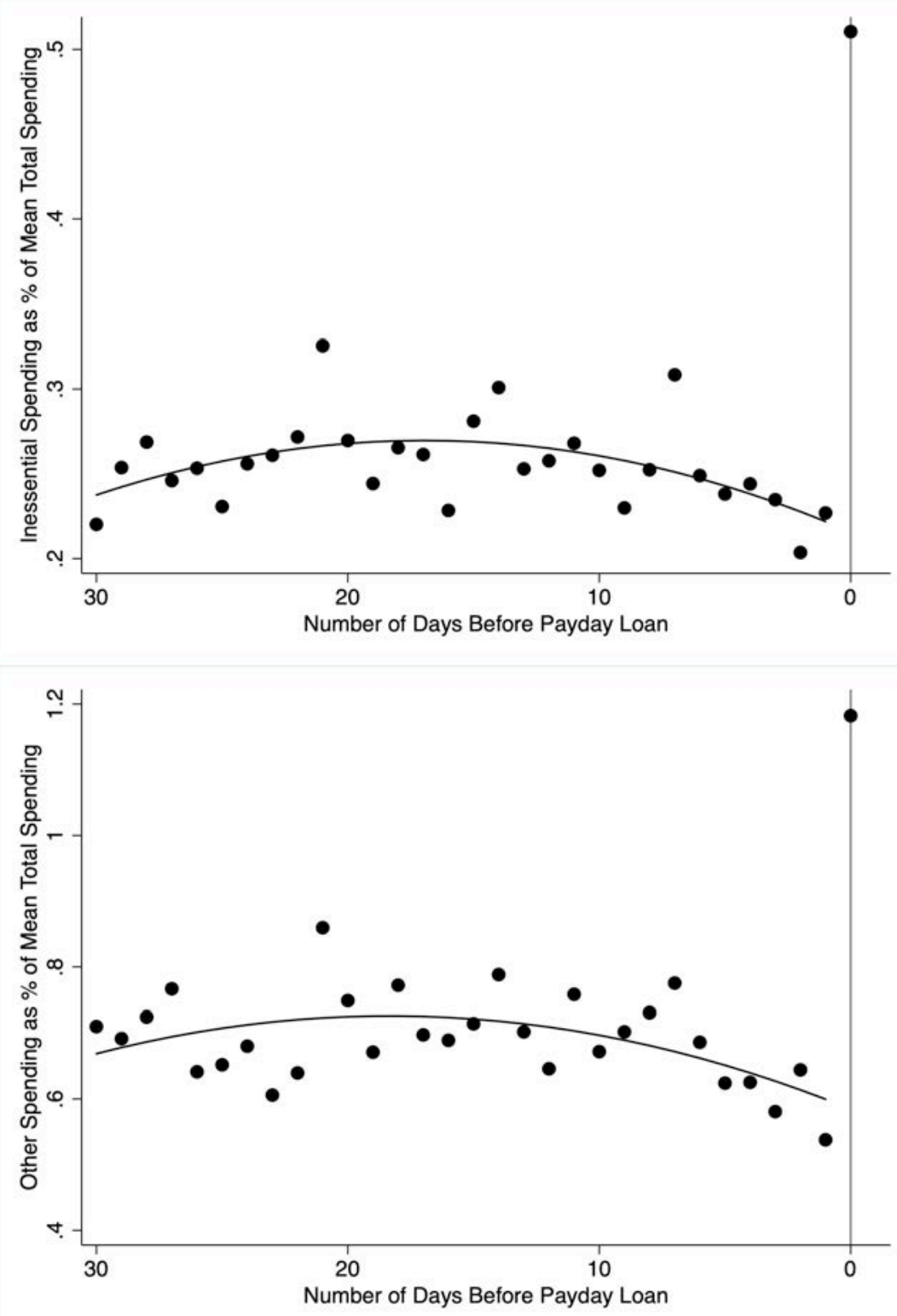

Note: This figure shows event studies of spending 30 days before a payday loan was taken. The top panel shows an event study for inessential spending - i.e., alcohol, food and drink out, recreation, lotteries, and gambling - as a fraction of daily average spending. The bottom panel shows an event study for all other spending, measured as a fraction of daily average spending. They adjust for day-of-the-week and calendarday-of-the-month effects (see Appendix). The curves show pre-loan quadratic trends. The analysis uses data on payday loans taken between January 31, 2011 and January 1, 2017. 2,660 loans were taken during this period by 627 participants. 


\section{Experimental Protocols}

Analysis of the administrative data, alone, indicate that "misfortune" is a primary driver of demand for high-cost credit, but that "mistakes" also play a role. Payday borrowers in Iceland tend to have lower income and low liquidity, on average. They also tend to be more illiquid in the days just before receiving the loan. While some of this illiquidity might be the product of earlier "mistakes," perhaps even an earlier decision to take a payday loan, a simple test for dominated choices provides evidence that, for most borrowers, this is not the case. Only $25 \%$ of borrowers have access to at least a week's worth of spending in cheaper liquidity and thus reveal a clear role for "mistake" in driving demand for payday loans. The results on spending provide little evidence of financial crisis or unusual deprivation in the days leading up to the loan. Consistent with this view, at least a small fraction of payday loan dollars is spent on consumption that could be easily postponed or substituted for a cheaper option.

The evidence on liquidity favoring misfortune may, however, be conservative because, even among those who have no access to cheaper market credit, the choice to take a payday loan may not be best. Indeed, many people with low income and liquidity choose not to borrow from payday lenders, and even those who turn to payday loans when they are especially illiquid do not always do so.

To further examine what underlies the heterogeneity in decisions to take payday loans, and evaluate the role of "mistakes," we therefore relate preferences and DMA as measured in the experiments to demand for payday loans.

\section{Recruitment \& Survey Design}

Meniga sent a subset of its clients in Iceland an email with an invitation and a link to an online survey that we designed and programmed. 8,913 e-mail invitations to users with complete records were successfully delivered. Of those, 1,701 (19.8\%) completed the survey. Compared with similar studies, this is a relatively high response rate. Epper et al. (2018), e.g., report 13\% and Andersson et al. (2016) report 11\%.

The survey contained three experimental tasks - a risk, an ambiguity, and an intertemporal choice task - and a brief questionnaire with questions about education, household composition, assets and debt. Participants earned on average \$25 for their participation and for the incentives. 
Payments ranged from $\$ 5$ to $\$ 63$ with a median payment of $\$ 18$. We discuss our sample and then the experimental tasks in detail.

\section{Sample}

Table 4 compares the survey sample to a nationally representative sample. Statistics Iceland reports that in 2017 the average age among those above age 15 was 45.3 and that women constituted $50 \%$ of the population. The average age in the survey sample is 43.5 and the share of women is $47 \%$. The share of singles in our survey is lower and the share of individuals living with a spouse and children is higher than in the overall population. Besides selection, this discrepancy may also be explained by the fact that individuals who live with a spouse (and possibly children), but are not registered as such, are counted by Statistics Iceland as living alone.

\section{Table 4: Comparison of Survey Sample to Icelandic Population}

\begin{tabular}{rcc} 
& $\begin{array}{c}\text { Survey } \\
\text { Participants }\end{array}$ & $\begin{array}{c}\text { Icelandic } \\
\text { Population }\end{array}$ \\
\cline { 2 - 3 } Female & $47 \%$ & $50 \%$ \\
Age & 43.5 & 45.3 \\
Labor Income & 4,343 & 4,153 \\
Family Composition & & \\
Spouse & $29 \%$ & $28 \%$ \\
Single & $23 \%$ & $42 \%$ \\
Spouse and children & $43 \%$ & $25 \%$ \\
Single and children & $6 \%$ & $5 \%$ \\
& & \\
Highest Degree Obtained & & \\
Mandatory education & $9 \%$ & $39 \%$ \\
Journeyman's examination & $4 \%$ & $5 \%$ \\
Master of a certified trade & $3 \%$ & $6 \%$ \\
Matriculation examination & $11 \%$ & $8 \%$ \\
Tertiary education & $8 \%$ & $15 \%$ \\
Technical degree & $5 \%$ & $2 \%$ \\
Bachelor & $30 \%$ & $15 \%$ \\
Master & $30 \%$ & $7 \%$ \\
Ph.D. & $2 \%$ & $1 \%$ \\
Other & $0 \%$ & $3 \%$
\end{tabular}

Note: This table compares survey participants to the general Icelandic population. 
Table 4 also compares the education of our sample to the education of the Icelandic population. The largest difference is in the share of individuals who have only completed mandatory education. The difference may be partly explained by differences in measurement. Statistics Iceland receives information on graduates directly from the educational institutions. This means that degrees obtained abroad are not registered. Icelanders who get university degrees abroad, which is common, would be registered as having only completed mandatory education.

Appendix Table 9 compares the survey sample to Meniga users with complete records. Despite the large sample size of the administrative data, we cannot reject the hypothesis that these two groups have similar liquidity, income, and demand for payday loans. There are some differences, however, in terms of the number and amount of non-sufficient funds charges.

\section{Experimental Tasks}

\section{Risk Task}

Participants allocated an experimental endowment of $500 \mathrm{kr}$. (appr. \$5) across 2 or 5 risky assets. The assets paid different amounts depending on whether a ball drawn from an urn was black or white. Participants were informed that the urn had 5 black balls and 5 white balls. Their decisions involved choosing how much to invest in each asset. Participants were presented with 15 investment problems (one of the 15 problems was randomly selected for payment). In the first 8 investment problems, there were 2 assets. In the last 7 investment problems, there were 5 assets. We varied the asset returns across the investment problems.

To illustrate, Online Appendix Figure 1 shows a screenshot of the interface for the problems with two assets. The table at the top of the screen shows the returns of assets A and B per $1 \mathrm{kr}$. invested. The participant was then prompted to make her investment choices. The graph below the table displays two bars: the first bar shows the amount invested in asset A; the second bar shows the amount invested in asset B. Participants made their investments by either dragging the bars up and down or by clicking on the + and - buttons. The interface was such that participants always invested $100 \%$ of their experimental endowment. A similar interface was used in the

investment problems with 5 assets (see Online Appendix Figure 2). The only distinction is that they were shown information about 5 assets - A, B, C, D, and E - and the graph displayed 5 bars. 
Half of the participants were randomly selected to be offered the option of avoiding the investment problem (Carvalho and Silverman 2019). In particular, these participants were offered the choice between making the investment decision or taking an outside option of $-50 \mathrm{kr}$., $0 \mathrm{kr}$., or $100 \mathrm{kr}$. The amount of the outside option was varied across the investment problems. The participant was paid the outside option if in the problem selected for payment she chose to avoid. Appendix Table 1 shows the parameters of the 15 decision problems.

The interfaces for the participants with the outside option were slightly different. Online Appendix Figure 3 shows a screenshot. It differs from the interface used by other participants (Appendix Figure 1) in two ways. First, the graph with the bars is not shown. Second, the prompt to invest ("You will choose the amount you want to invest on each asset.") is replaced by a prompt for the participant to choose between investing the experimental endowment (button "Invest Y kr.") and taking the outside option (button "Receive X kr."). If she clicked on the first button, the bars were unveiled and she could make her investment choices using the same interface used by other participants. If she clicked on the second button, she saw the next decision problem.

\section{Ambiguity Task}

The ambiguity task was similar to the risk task with 3 distinctions. First, participants were informed that the urn now had 8 balls of one color and 2 balls of the other. However, they did not know whether the urn had 8 black balls and 2 white or if it had 2 black and 8 white. Second, in all 15 investment problems there were just 2 assets. Third, participants were not offered the option of avoiding the investment problem. Appendix Table 2 shows the parameters of the 15 investment problems. As in the risk task, 1 of the 15 problems was randomly selected for payment.

\section{Intertemporal Choice Task}

Participants had to allocate their experimental endowment across a sooner date and a later date. The amount allocated to the later date accrued an experimental interest rate. Participants were presented with 12 intertemporal allocation problems ( 1 of the 12 problems was randomly selected

for payment). We varied the experimental endowment, the experimental interest rate, and the sooner date across the problems. In the first 6 problems, the sooner date was today. In the last 6 problems, the sooner date was one year away. The time interval between the sooner and later dates 
was always one month. Within a time frame, the interest rate increased monotonically. Appendix Table 3 shows the parameters of the 12 intertemporal allocation problems.

Online Appendix Figure 4 shows a screenshot of the interface for the intertemporal choice task. Two calendar sheets at the top of the screen show the sooner date (calendar sheet on the left) and the later date (calendar sheet on the right). The graph below the calendar sheets displays two bars: the bar on the left shows the amount to be received at the sooner date; the bar on the right shows the amount to be received at the later date (including the interest accrued).

\section{Measuring Decision-making Ability (DMA)}

Our main measure of DMA is a composite that reflects the internal consistency of choices in the risk and ambiguity tasks. We exploit the within-subject variation in asset returns to construct individual-specific measures of DMA for each task. In the ambiguity task, we study whether choices violate the Generalized Axiom of Revealed Preference (GARP) ${ }^{10}$ In the risk task, we use different measures depending on whether the participant had the option to avoid the investment problem. We study whether the choices of those with the option to avoid the investment problem violate monotonicity with respect to first-order stochastic dominance (FOSD) and whether the choices of those without such option violate GARP and FOSD (Polisson et al. 2019).

Choi et al. (2014) and Kariv and Silverman (2013) argue that consistency with GARP is a necessary condition for high quality decision-making. This view draws on Afriat (1967), which shows that if an individual's choices satisfy GARP in a setting like the one we study, then those choices can be rationalized by a well-behaved utility function. Consistency with GARP thus implies that the choices can be reconciled with a single, stable objective. We assess how nearly individual choice behavior complies with GARP using Afriat's (1972) Critical Cost Efficiency Index (CCEI). The CCEI is a number between zero and one, where one indicates perfect consistency with GARP. The degree to which the index falls below one may be viewed as a measure of the severity of the GARP violations.

Consistency with GARP may be too low a standard of DMA because it treats all stable objectives of choice as equally high-quality. A stronger requirement would require monotonicity

\footnotetext{
${ }^{10}$ In the intertemporal choice task, we calculated CCEI separately using the choices for a given time frame and then took the minimum of the CCEI across the two time frames.
} 
of preferences. Specifically, violations of monotonicity with respect to first-order stochastic dominance (FOSD) - choices that yield payoff distributions with unambiguously lower payoffs than available options - may be seen as errors and provide a criterion for decision-making quality. ${ }^{11}$

We use the distribution of possible payoffs to assess how closely individual choices comply with this dominance principle. To illustrate a violation of FOSD, consider a simplified case with two assets and no outside option. Asset 1 pays $B$ if a black ball is drawn and 0 if a white ball is drawn. Asset 2 pays 0 if a black ball is drawn and $W$ if a white ball is drawn. Let $a$ be the amount invested on asset 1 . The remaining $500-a$ are invested on asset 2 . Investing $a^{R F}$ on asset 1 and $500-a^{R F}$ on asset 2 is the risk-free allocation that pays the same amount irrespective of the color of the ball drawn, i.e., $a^{R F} B=\left(500-a^{R F}\right) W$.

Suppose that asset 1 has a higher return than asset 2, i.e., $B>W$, and that a participant chooses to invest less on asset 1 than the amount invested in the risk-free allocation, i.e., $a<a^{R F}$. In this case, investing $a^{\prime}=500-a B / W$ on asset 1 yields an unambiguously higher payoff distribution than investing $a$ on asset 1 . First, notice that the minimum payout when investing $a$ (black ball is drawn) is equal to the minimum payout when investing $a^{\prime}$ (white ball is drawn): $a B$. Second, the expected return of investing $a^{\prime}, 250+a^{\prime}(B-W) / 2$, is higher than the expected return of investing $a, 250+a(B-W) / 2$, because $B>W$ and $a^{\prime}>a$.

Following Choi et al. (2014), we calculated a FOSD score as follows. If the selected investment portfolio was dominated as in the example above, the FOSD score was calculated as $\frac{250 W+a(B-W) / 2}{250 W+a^{\prime}(B-W) / 2}$, which equals the expected return of the selected allocation as a fraction of the maximal expected return. The availability of the outside option introduces more opportunities for violating FOSD. First, if the participant invests $a<a^{R F}$ on asset 1 and the outside option is greater

\footnotetext{
${ }^{11}$ Our approach to measuring decision-making ability is related to von Gaudecker, et al. (2011). That paper also studied behavior in choice experiments but estimated a flexible parametric model that includes an individual-level parameter $\omega_{i}$ that gives the propensity of individual $i$ to choose randomly rather than on the basis of preferences. That parameter can be interpreted as an individual measure of decision-making ability as it captures a tendency for an individual to be consistent both with rationality and with some assumptions about the functional form of utility. This is different from our approach in that, rather than make additional assumptions about the structure of preferences, we rely only on consistency with utility maximization and on consistency with monotonicity.
} 
than $250+a(B-W) / 2$, then investing $a$ is dominated both by investing $a^{\prime}=500-a B / W$ and by the outside option, in which case we calculated the FOSD score as $\frac{250 W+a(B-W) / 2}{\max \left\{250 W+a^{\prime}(B-W) / 2, \text { outside option }\right\}}$. Second, the participant violates FOSD by investing $a>a^{R F}$ if the outside option is greater than $250+a(B-W) / 2$-in this case we calculated the FOSD score as $\frac{250 W+a(B-W) / 2}{\text { outside option }}$. Finally, one violates FOSD by taking the outside option if it is lower than the risk-free return, $250+a^{R F}(B-W) / 2$, in which case the FOSD was calculated as $\frac{\text { outside option }}{250+a^{R F}(B-W) / 2}$. The FOSD score was assigned a value of 1 if there was no FOSD violation.

We also calculate a unified measure of violations of GARP and of monotonicity with respect to FOSD, following Polisson et al. (2019). This measure, like the CCEI, lies between 0 and 1 where 1 represents perfect consistency with both GARP and monotonicity with respect to FOSD.

To reduce the influence of measurement error on estimates, we constructed a composite measure of DMA derived from the risk and ambiguity tasks. We first calculated participants' percentile ranks in the distribution of DMA in each task. For the risk task in particular, we calculated separate percentile ranks for those participants who had the option of avoiding the investment problem and those who did not. For the first group, we calculated their percentile ranks in the distribution of the measure of FOSD violations. For the second group, we calculated their percentile ranks in the distribution of the unified measure of GARP and FOSD violations. Finally, we constructed a DMA index as the first component of a principal component analysis of the measures of DMA in each one of the two tasks. ${ }^{12}$

In Section VI, we assess the validity of this index by evaluating its ability to predict an unambiguous mistake revealed in the administrative data. That mistake, the accrual of insufficient fund fees which produce no benefit to the consumer, is strongly correlated with this principal component index of consistency with utility maximization.

As an alternative to the principal component approach to measurement error, we adopt the Obviously Related Instrumental Variables (ORIV) approach (Cf. Gillen et al., 2019). That approach uses DMA derived from the risk task as an instrument for the DMA derived in the

\footnotetext{
12 The first principal component explains about two-thirds of the variation. It loads equally on the DMA from the risk task and the DMA from the ambiguity task such that it is virtually equivalent to taking an average of the two.
} 
ambiguity task while also using the ambiguity DMA to instrument for the risk DMA. See Appendix Table 6 for details. The two approaches produce qualitatively similar results.

\section{Measuring Time and Risk Preferences}

To avoid a multiple indicators problem and better distinguish between DMA and preferences, both time preferences and risk preferences, identified with the curvature of the utility function, are derived from the intertemporal choice task. ${ }^{13}$ Let $s_{i, r}^{0}$ be the fraction of the endowment allocated by participant $i$ in the intertemporal choice task to the sooner date when the sooner date is today and the interest rate is $r$ and let $s_{i, r}^{1}$ be the fraction allocated by $i$ to sooner when the sooner date is one year away. We measured $i$ 's impatience as the average of $s_{i, r}^{1}$ across the 5 different positive $r^{\prime} s$. Define $\Delta_{i, r} \equiv s_{i, r}^{0}-s_{i, r}^{1}$. We measured the present bias of $i$ as the average of $\Delta_{i, r}$ across all $6 r^{\prime} s$. Participant $i$ was classified as present-biased if this average was positive, time consistent if zero, and future-biased if negative. Define $d_{i, r, r^{\prime}}^{k} \equiv\left(s_{i, r}^{k}-s_{i, r^{\prime}}^{k}\right) /\left(r^{\prime}-r\right)$ for $k=\{0,1\}$. The intertemporal elasticity of substitution was measured as the average of $d_{i, r, r^{\prime}}^{k}$ across the five interest rate increases and across $k$. Curvature of the utility function is defined as the inverse of the intertemporal elasticity of substitution. We show in Appendix Table 5 that we obtain similar results if we use a measure of risk aversion constructed from the risk task.

In Appendix Table 10, we assess the validity of these measures of preferences by evaluating whether they reproduce associations documented in previous work. The table shows that they predict the relevant outcomes in expected ways: impatience predicts wealth (as in Epper et al. 2018); present bias predicts consumer debt (as in Meier and Sprenger 2010); and risk aversion predicts stock market participation (as in Barsky et al. 1997). ${ }^{14}$

\section{Experimental Results}

Those who exhibit lower DMA in the experiments make greater use of payday loans. Figure 3 shows averages of the number of payday loans (left y-axis) and of total amount borrowed

\footnotetext{
${ }^{13}$ Participants very rarely violated GARP in the intertemporal choice task, which gives us greater assurance that we are capturing preferences rather than a mix of preferences and DMA.

${ }^{14}$ Data on wealth and stock market participation come from the survey. Participants reported the value of different types of assets, including stocks. Information about overdraft balances come from the administrative data.
} 
(right y-axis), by terciles of the DMA distribution. The number above a bar is the p-value of a test of differences in means between that bar and the one to its left. For example, the 0.064 above the second bar is the p-value of a test of the difference between the middle and bottom terciles of the DMA distribution in the number of payday loans. Individuals in the bottom tercile of the distribution of the DMA index have on average approximately 1 payday loan more than individuals in the top tercile of the distribution of DMA. They borrowed on average 3 times more.

Figure 3: Payday Loans and Decision-Making Ability

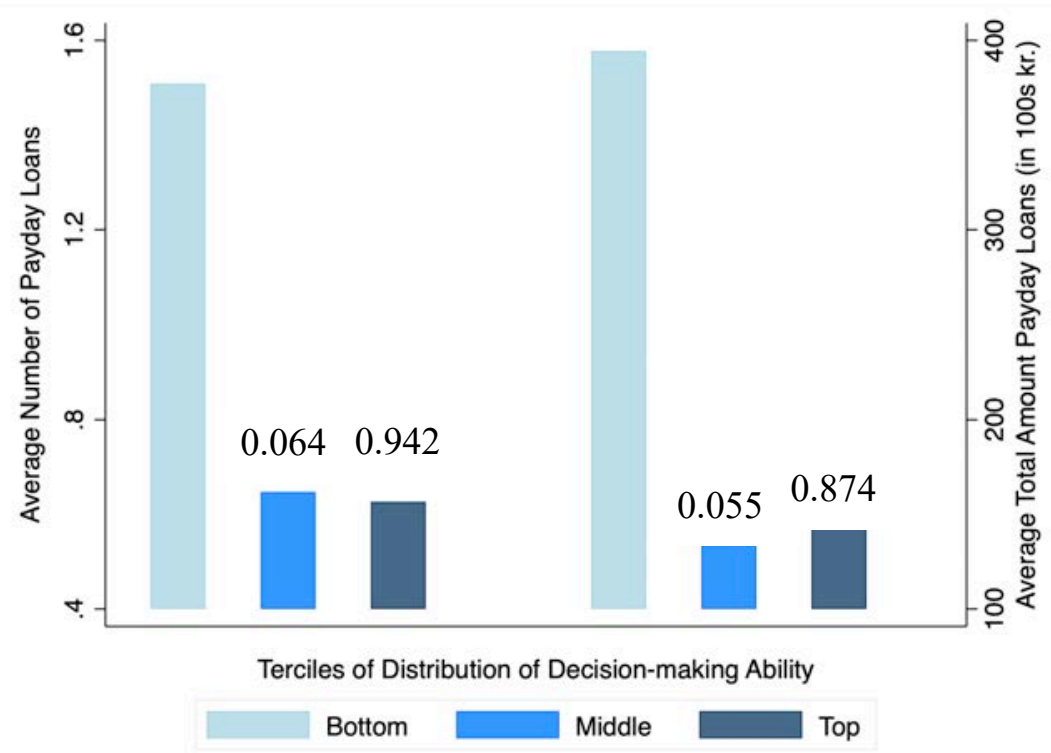

Note: This figure shows the use of payday loan services (over a period of 73 months) by decision-making ability. The three bars on the left show the average number of payday loans per individual for individuals in the bottom, middle, and top terciles of the decision-making ability distribution. The three bars on the right show the average amount per individual of all payday loans for individuals in the bottom, middle, and top terciles of the decision-making ability distribution. Number of participants is equal to 576 in each tercile for a total of 1,728 . The number above a bar reports the p-value of a test of the difference between the bar and the bar to its left.

Payday loans are rare in the population, so the average level differences in borrowing by quantiles of the DMA distribution may understate the importance of those with low ability in the payday loan market. Indeed, lower-DMA people appear to play an outsized role in this market. Table 5 shows the share of the total amount borrowed by percentile of the DMA distribution. Those in the bottom $10 \%$ borrowed $29 \%$ of the total. The bottom $20 \%$ of the DMA distribution borrowed 
almost half of the total amount borrowed. In contrast, those at the top $10 \%$ borrowed less than $1 \%$ of the total amount.

Table 5: Cumulative Share of Total Amount Borrowed by Percentile of Decision-Making Ability Distribution

\begin{tabular}{ccccccccc}
\hline \multicolumn{7}{c}{ Percentile of Decision-Making } & Quality Distribution \\
10 th & 20th & 30th & 40th & 50th & 60th & 70th & 80th & 90th \\
\hline $29 \%$ & $45 \%$ & $57 \%$ & $68 \%$ & $76 \%$ & $78 \%$ & $87 \%$ & $89 \%$ & $99 \%$ \\
\hline
\end{tabular}

Note: This table shows the share of the total amount of payday loans borrowed by individuals in the bottom $X^{\text {th }}$ percentile of the decision-making ability distribution as a fraction of the total amount of all payday loans taken by survey participants. For example, together the payday loan borrowers borrowed a total of $\$ 388,082$. Those individuals in the bottom $20^{\text {th }}$ percentile of the decision-making ability distribution borrowed collectively a total of $\$ 174,646$. Number of participants $=1,728$.

The strong association between payday loans and DMA may partly reflect individual differences in preferences or liquidity. Figure 4 documents the association of payday loans and of DMA with these potential confounders. The panels show averages of the number of payday loans (left y-axis) and of the percentile rank in the distribution of DMA (right y-axis), separately by impatience, present bias, small-stakes risk aversion, and by liquidity. A participant's liquidity is the median, across all days, of the daily sum of savings and checking account balances, overdraft limit, and credit card limit minus balance.

The relationships between payday loan demand, preferences, and liquidity all go in the expected direction. Individuals who are more impatient, more present-biased, or have lower liquidity take on average more payday loans. The relationships between DMA and impatience and risk aversion are monotonic: the more impatient and more risk averse 
Figure 4: Association of Payday Loans and of Decision-making Ability with Economic Preferences and with Liquidity
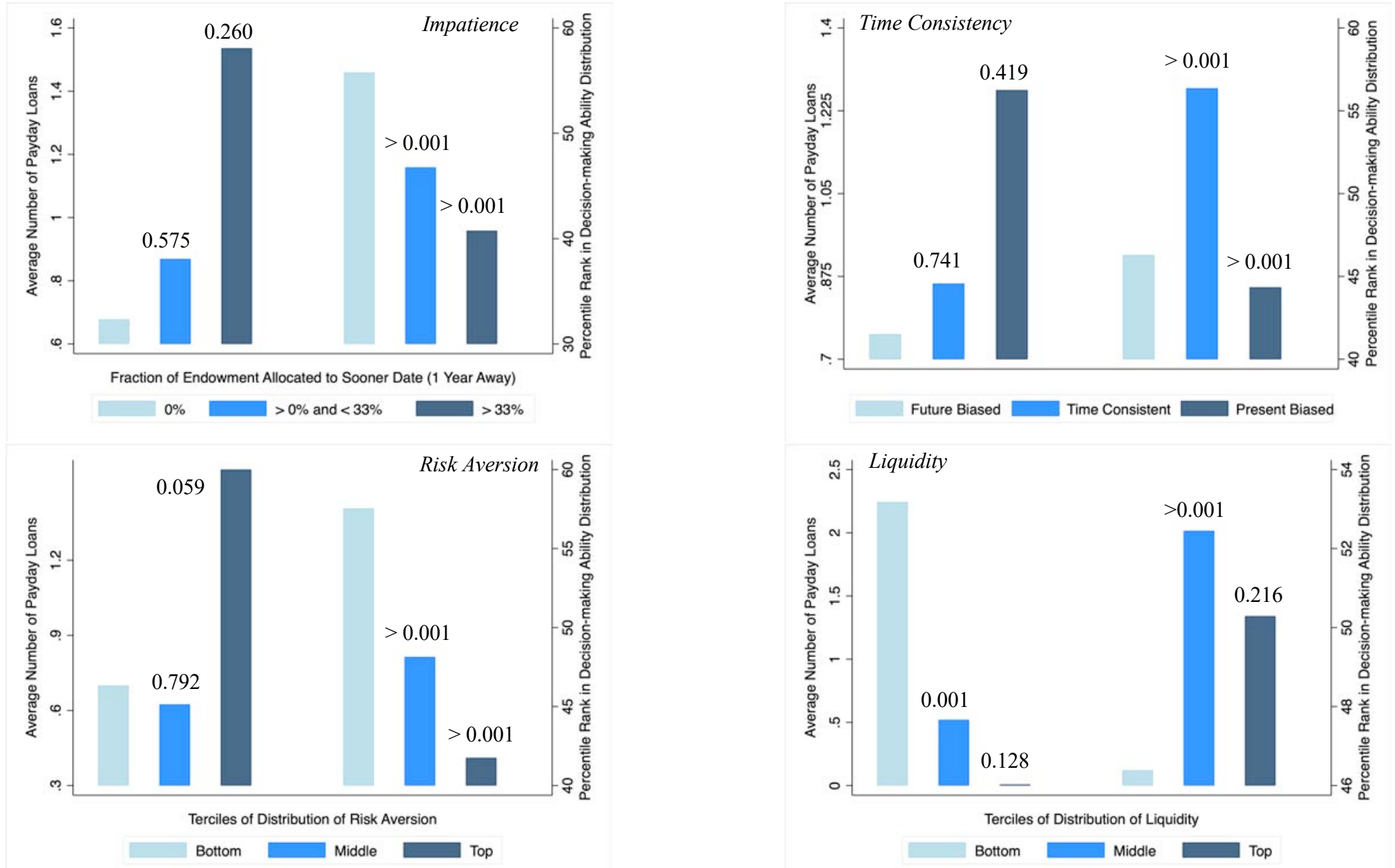
Note: This figure investigates the relationship between number of paydays loans and the percentile rank in the distribution of decision-making ability, on one hand, and impatience, time consistency, risk aversion, and liquidity, on the other. The left y-axis in the figures shows the average number of payday loans. The right y-axis shows the average percentile rank in the distribution of decision-making ability. The top left figure shows separate numbers for those who allocated $0 \%$ to the sooner date $(N=863)$; those who allocated more than $0 \%$ and less than $33 \%(N=405)$; and those who allocated more than $33 \%(N=433)$. The top right figure shows separate numbers for those who exhibited future-biased behavior $(N=535)$, time consistency $(N=686)$, and present-biased behavior $(N=480)-\operatorname{see}$ section for description of how we constructed these groups. The bottom figures show numbers for those in the bottom $(N=716$ and 535), middle $(N=514$ and 534), and top $(N=471$ and 534) terciles of the distribution of risk aversion and of the distribution of liquidity respectively. The number above a bar reports the p-value of a test of the difference between the bar and the bar to its left.

exhibit lower DMA. We also find that the present-biased exhibit substantially lower DMA than the time-consistent. Those in the bottom tercile of the distribution of liquidity have lower DMA than those in the middle and top terciles.

The results in Figure 4 suggest that the relationship between DMA and payday loans may be confounded by both economic preferences and liquidity. In Table 6, we use regression analysis to estimate the relationship between payday loan borrowing and DMA conditioning on these potential confounders. The dependent variable is the number of payday loans. The independent variables shown in the first 5 rows - DMA, liquidity, impatience, present bias, and risk aversion are measured in percentile ranks divided by 10 , such that the coefficients can be interpreted as the effects of increasing these variables in 10 percentiles. The liquidity measure here is the median of the daily sum of checking and savings balances plus overdraft and credit card limits minus the credit card balance. All regressions include controls for the log of average monthly income, years of schooling, gender, age, and age squared. ${ }^{15}$

The results in Table 6 indicate that both "misfortune" and "mistake" are important in determining payday loan borrowing. Individuals in worse financial circumstances and with lower DMA take more payday loans. The relationship between payday loans and DMA and the relationship between payday loans and liquidity are robust to controlling for demographics, education, income, and time and risk preferences. In the first three specifications, DMA is

${ }^{15}$ In Appendix Tables 4 and 5, we present the results of alternative specifications that allow for non-linear effects of liquidity or alternative measures of the potentially confounding variables. The point estimate of the relationship between DMA and loan demand is stable across specifications. 
statistically significant at the 5\% confidence level. Liquidity is always significant at the $1 \%$ level. Improving DMA in 10 percentiles reduces the number of payday loans by $0.16-0.21$ loans depending on the specification. Increasing liquidity in 10 percentiles reduces the number of payday loans by 0.47-0.49 loans. These estimates are not small given that the average number of payday loans is 0.94 and that as shown in Table 6 these loans are concentrated among the individuals with lower DMA. ${ }^{16}$

Table 6: Independent Effects of Liquidity and Decision-making Ability on Payday Loans

\begin{tabular}{|c|c|c|c|c|c|}
\hline \multirow[b]{2}{*}{ DMA } & \multicolumn{5}{|c|}{ Number of Payday Loans } \\
\hline & $\begin{array}{l}-0.21 \\
(0.08)\end{array}$ & & $\begin{array}{l}-0.17 \\
(0.07)\end{array}$ & $\begin{array}{l}-0.16 \\
(0.07)\end{array}$ & $\begin{array}{l}-0.16 \\
(0.07)\end{array}$ \\
\hline Liquidity & & $\begin{array}{l}-0.49 \\
(0.09)\end{array}$ & $\begin{array}{l}-0.48 \\
(0.09)\end{array}$ & $\begin{array}{l}-0.47 \\
(0.09)\end{array}$ & $\begin{array}{l}-0.47 \\
(0.08)\end{array}$ \\
\hline Impatience & & & & $\begin{array}{c}0.04 \\
(0.04)\end{array}$ & $\begin{array}{c}0.04 \\
(0.06)\end{array}$ \\
\hline Present Bias & & & & $\begin{array}{c}0.07 \\
(0.07)\end{array}$ & $\begin{array}{c}0.07 \\
(0.07)\end{array}$ \\
\hline Risk Aversion & & & & & $\begin{array}{c}-9.47 \mathrm{E}-05 \\
(0.06)\end{array}$ \\
\hline Log Income & $\begin{array}{c}0.05 \\
(0.14)\end{array}$ & $\begin{array}{c}0.67 \\
(0.20)\end{array}$ & $\begin{array}{c}0.69 \\
(0.21)\end{array}$ & $\begin{array}{c}0.69 \\
(0.21)\end{array}$ & $\begin{array}{c}0.69 \\
(0.21)\end{array}$ \\
\hline Years of Schooling & $\begin{array}{l}-0.08 \\
(0.05)\end{array}$ & $\begin{array}{l}-0.03 \\
(0.05)\end{array}$ & $\begin{array}{l}-0.02 \\
(0.05)\end{array}$ & $\begin{array}{l}-0.02 \\
(0.05)\end{array}$ & $\begin{array}{l}-0.02 \\
(0.05)\end{array}$ \\
\hline Female & $\begin{array}{l}-0.69 \\
(0.34)\end{array}$ & $\begin{array}{l}-0.82 \\
(0.35)\end{array}$ & $\begin{array}{l}-0.85 \\
(0.35)\end{array}$ & $\begin{array}{l}-0.90 \\
(0.37)\end{array}$ & $\begin{array}{l}-0.90 \\
(0.37)\end{array}$ \\
\hline Age & $\begin{array}{l}-0.01 \\
(0.02)\end{array}$ & $\begin{array}{c}0.01 \\
(0.02)\end{array}$ & $\begin{array}{c}3.73 \mathrm{E}-03 \\
(0.02)\end{array}$ & $\begin{array}{c}1.19 \mathrm{E}-03 \\
(0.02)\end{array}$ & $\begin{array}{c}1.20 \mathrm{E}-03 \\
(0.02)\end{array}$ \\
\hline $\mathrm{Age}^{2}$ & $\begin{array}{l}-9.09 \mathrm{E}-04 \\
(6.73 \mathrm{E}-04)\end{array}$ & $\begin{array}{l}-2.98 \mathrm{E}-04 \\
(6.82 \mathrm{E}-04)\end{array}$ & $\begin{array}{l}-4.25 \mathrm{E}-04 \\
(6.68 \mathrm{E}-04)\end{array}$ & $\begin{array}{l}-4.99 \mathrm{E}-04 \\
(6.56 \mathrm{E}-04)\end{array}$ & $\begin{array}{c}-4.99 \mathrm{E}-04 \\
(6.57 \mathrm{E}-04)\end{array}$ \\
\hline $\mathrm{R}^{2}$ & 0.01 & 0.03 & 0.04 & 0.04 & 0.04 \\
\hline
\end{tabular}

Notes: This table investigates the relationship between payday loan borrowing, decisionmaking ability, and liquidity. The mean of the dependent variable is 0.94 . Decision-making ability, liquidity, time preferences and risk preferences are measured in percentile ranks divided by 10 . Number of observations $=1,573$.

\footnotetext{
${ }^{16}$ Applying an instrumental variables (IV) approach to measurement error in DMA (Gillen et al., 2019), suggests these estimates may be understating the magnitude of the relationship between DMA and payday loans. The approach uses DMA derived from the risk task as an instrument for the DMA derived in the ambiguity task while also using the ambiguity DMA to instrument for the risk DMA. The results of Appendix Table 6 show that the IV point estimate of the relationship between DMA and the number of loans is more than twice the OLS estimate.
} 
Impatient and present-biased individuals take more payday loans, but these point estimates are relatively imprecise. Income and gender also have substantial, independent relationships with demand for payday loans. Women take, on average, one less loan than men and the point estimate indicates a $10 \%$ increase in average income is associated with a 0.07 increase in the number of payday loans received. The counterintuitive, positive relationship with income derives from conditioning on liquidity. The coefficient on income is not statistically distinguishable from zero with conventional levels of confidence when we do not condition on measures of liquidity.

Appendix Table 4 shows that the relationship is robust to controlling for liquidity more flexibly. Appendix Table 5 shows, in turn, that the estimated relationship between DMA and payday loans is robust to using alternative measures of demographics, education, liquidity, income, and risk preferences.

\section{Interactions Between "Misfortune" and "Mistake"}

The results in Table 6 assume that liquidity and DMA have separable effects on payday loan borrowing, but it is plausible that the influence of one is affected by the level of the other. Figure 5 provides preliminary evidence that this is the case. It divides the sample roughly into quarters by high- and low-liquidity and by high- and low-DMA. It then displays the average number of payday loans for each quarter of the sample.

Figure 5 shows that - regardless of DMA - those in the top half of the liquidity distribution virtually never take payday loans. Among the bottom half of the liquidity distribution, however, those with lower DMA take three times as many loans as those with higher DMA. Table 7 further investigates these results in a regression framework that controls for demographics, income, and economic preferences.

In particular, Table 7 presents the results of a regression of the number of payday loans on liquidity, DMA, and the interaction of the two (both are demeaned). The effect of an increase in DMA of 10 percentiles is equal to the coefficient on the interaction term times liquidity plus the coefficient on DMA. Similarly, the effect of an increase in liquidity of 10 percentiles is equal to the coefficient on the interaction term times DMA plus the coefficient on liquidity. To illustrate, if an individual is at the $60^{\text {th }}$ percentile of the DMA distribution, the effect of a reduction in 
liquidity of 10 percentiles is equal to the coefficient on the interaction term minus the coefficient on liquidity.

\section{Figure 5: Average Number of Payday Loans by Liquidity $\times$ Decision-Making Ability}

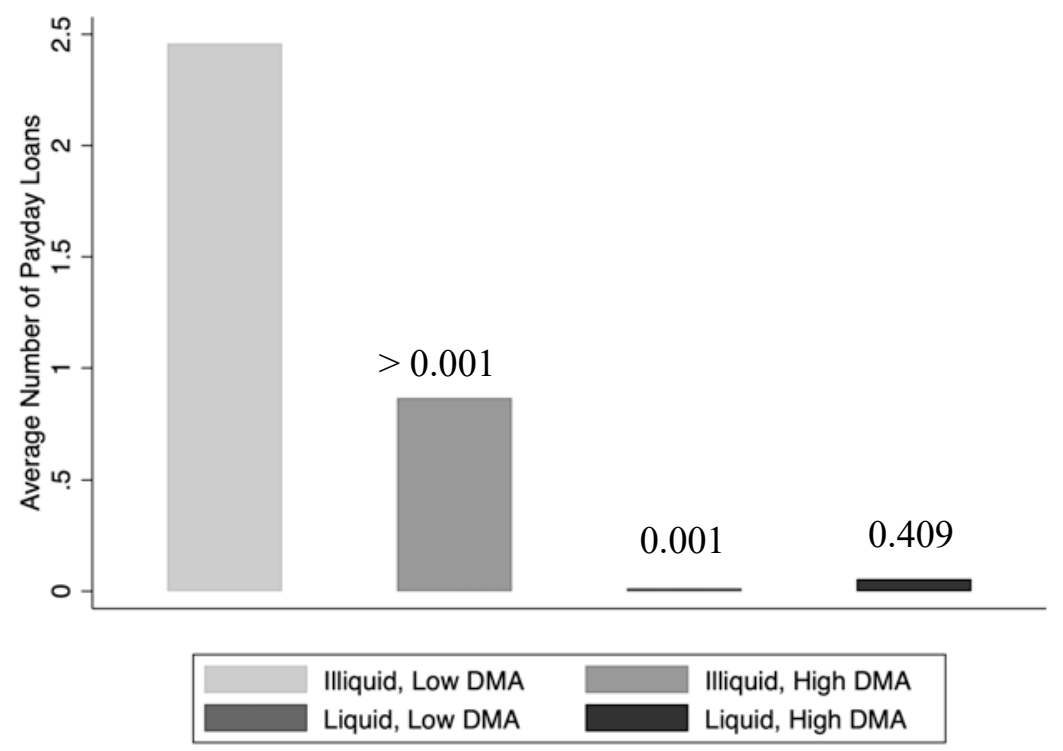

Note: This figure shows the average number of payday loans for four different groups: 1) those in the bottom half of the liquidity distribution and the bottom half of the decision-making ability distribution ("Illiquid, Low DMA"); 2) those in the bottom half of the liquidity distribution and the top half of the decision-making ability distribution ("Illiquid, High DMA"); 3) those in the top half of the liquidity distribution and the bottom half of the decision-making ability distribution ("Liquid, Low DMA"); and 4) those in the top half of the liquidity distribution and the top half of the decision-making ability distribution ("Liquid, High DMA"). The number of participants in each group is respectively $484,443,384$, and 417 for a total of 1,728 participants. The number above a bar reports the p-value of a test of the difference between the bar and the bar to its left.

The first column of Table 7 reproduces the middle column of Table 6 for comparison. In the second column, we add the interaction term. The coefficients on DMA and on liquidity barely change. Time preferences are included in the third column while risk preferences are included in the fourth column. These results confirm that higher DMA protects against the negative effects of illiquidity. The coefficient on liquidity in the fourth column is -0.46 . The coefficient on the interaction term, which is statistically significant at the $1 \%$ level, is 0.07 . This implies that a reduction in liquidity in 10 percentiles increases the number of payday loans by 0.73 for someone in the $10^{\text {th }}$ percentile of the distribution of DMA, by 0.46 for someone with median DMA, and by 0.18 for someone in the $90^{\text {th }}$ percentile. Similarly, the effect of lower DMA is decreasing in liquidity. A reduction in DMA in 10 percentiles increases the number of payday loans by 0.44 for 
someone in the 10th percentile of the distribution of liquidity and virtually has no effect on the number of payday loans of someone in the 70th percentile.

Table 7: Interactive Effects of Liquidity and Decision-making Ability on Payday Loans

\begin{tabular}{|c|c|c|c|c|}
\hline \multirow[b]{2}{*}{ DMA * Liquidity } & \multicolumn{4}{|c|}{ Number of Payday Loans } \\
\hline & & $\begin{array}{c}0.07 \\
(0.02)\end{array}$ & $\begin{array}{c}0.07 \\
(0.02)\end{array}$ & $\begin{array}{c}0.07 \\
(0.02)\end{array}$ \\
\hline DMA & $\begin{array}{l}-0.17 \\
(0.07)\end{array}$ & $\begin{array}{l}-0.18 \\
(0.07)\end{array}$ & $\begin{array}{l}-0.16 \\
(0.07)\end{array}$ & $\begin{array}{l}-0.16 \\
(0.07)\end{array}$ \\
\hline Liquidity & $\begin{array}{l}-0.48 \\
(0.09)\end{array}$ & $\begin{array}{l}-0.47 \\
(0.08)\end{array}$ & $\begin{array}{l}-0.46 \\
(0.08)\end{array}$ & $\begin{array}{l}-0.46 \\
(0.08)\end{array}$ \\
\hline Impatience & & & $\begin{array}{c}0.03 \\
(0.04)\end{array}$ & $\begin{array}{c}0.03 \\
(0.06)\end{array}$ \\
\hline Present Bias & & & $\begin{array}{c}0.07 \\
(0.07)\end{array}$ & $\begin{array}{c}0.07 \\
(0.07)\end{array}$ \\
\hline Risk Aversion & & & & $\begin{array}{c}2.76 \mathrm{E}-03 \\
(0.06)\end{array}$ \\
\hline Log Income & $\begin{array}{c}0.69 \\
(0.21)\end{array}$ & $\begin{array}{c}0.72 \\
(0.21)\end{array}$ & $\begin{array}{c}0.72 \\
(0.21)\end{array}$ & $\begin{array}{c}0.72 \\
(0.21)\end{array}$ \\
\hline Years of Schooling & $\begin{array}{l}-0.02 \\
(0.05)\end{array}$ & $\begin{array}{l}-0.02 \\
(0.05)\end{array}$ & $\begin{array}{l}-0.02 \\
(0.05)\end{array}$ & $\begin{array}{l}-0.02 \\
(0.05)\end{array}$ \\
\hline Female & $\begin{array}{l}-0.85 \\
(0.35)\end{array}$ & $\begin{array}{l}-0.78 \\
(0.35)\end{array}$ & $\begin{array}{l}-0.83 \\
(0.36)\end{array}$ & $\begin{array}{l}-0.83 \\
(0.36)\end{array}$ \\
\hline Age & $\begin{array}{c}3.73 \mathrm{E}-03 \\
(0.02)\end{array}$ & $\begin{array}{c}3.58 \mathrm{E}-03 \\
(0.02)\end{array}$ & $\begin{array}{c}1.16 \mathrm{E}-03 \\
(0.02)\end{array}$ & $\begin{array}{c}1.05 \mathrm{E}-03 \\
(0.02)\end{array}$ \\
\hline $\mathrm{Age}^{2}$ & $\begin{array}{c}-4.25 \mathrm{E}-04 \\
(6.68 \mathrm{E}-04)\end{array}$ & $\begin{array}{l}-3.62 \mathrm{E}-04 \\
(6.73 \mathrm{E}-04)\end{array}$ & $\begin{array}{c}-4.38 \mathrm{E}-04 \\
(6.61 \mathrm{E}-04)\end{array}$ & $\begin{array}{l}-4.38 \mathrm{E}-04 \\
(6.62 \mathrm{E}-04)\end{array}$ \\
\hline $\mathrm{R}^{2}$ & 0.04 & 0.05 & 0.05 & 0.05 \\
\hline
\end{tabular}

Notes: This table investigates the relationship between payday loan borrowing, decision-making ability, and liquidity. The mean of the dependent variable is 0.94 . Decision-making ability, liquidity, time preferences and risk preferences are measured in percentile ranks divided by 10 . Number of observations $=1,573$.

\section{Decision-making Ability and High-Frequency Variation in Liquidity}

The prior results indicate DMA plays a meaningful role in determining demand for payday loans, especially for those with low average liquidity. These results may, however, overstate the 
relative importance of DMA and, by implication, "mistakes" because they account only for an individual's median financial circumstances over a relatively long period. While DMA may be quite stable over time, liquidity often is not and averaging over the sample period may gloss over the key liquidity events that drive high-cost credit demand.

To investigate this possibility, we estimate analogous relationships between financial circumstances and high-cost loan demand at the daily level, conditional on demographics, DMA and preferences. Table 8 presents the results, where the unit of observation is now the individualday, the dependent variable is an indicator for whether the individual received a payday loan that day, and liquidity is measured on the day before the loan was received. Standard errors on the point estimates are clustered at the level of the individual.

In specification (1) of Table 8 we find, as in the low-frequency specifications, a negative relationship between DMA and payday loan demand, conditional on average income, education, and demographics. Given the low probability of taking a loan on any given day, the magnitude of the point estimate is correspondingly smaller, but is again statistically distinguishable from zero with high confidence. In specification (2), we also condition on liquidity levels the day before, and find, as expected, a significant negative relationship. Importantly, however, adding this daily measure of the level liquidity has no meaningful impact on the point estimate of the relationship between DMA and payday loan demand. As in the low-frequency specifications, adding controls for preferences in specifications (3) and (4) alters the estimated relationship between DMA and payday loan demand only modestly. To account for the frequency of zeros and outliers in the liquidity distribution, specification (5) replaces the level measure of liquidity with its inverse hyperbolic sign.

Finally, specification (6) evaluates the possibility that the circumstances which represent a liquidity "crisis" depend on an individual's typical liquidity. While each specification has, so far, conditioned on measures of average income and education, the situations that trigger an individual's demand for a payday loan may depend on the extent to which liquidity has fallen below its usual levels. In this last specification, therefore, we replace the daily liquidity level with its within-individual percentile rank. The results show, that the relative level of financial 
circumstances is a significant predictor of payday loan demand, but conditioning on it has little influence on the estimated relationship between DMA and the likelihood of taking a payday loan. ${ }^{17}$

Table 8: Decision-making Ability and High-Frequency Variation in Liquidity

\begin{tabular}{|c|c|c|c|c|c|c|}
\hline & & & 1 if Took a & day Loan & & \\
\hline & (1) & (2) & (3) & (4) & (5) & (6) \\
\hline DMA & $\begin{array}{l}-1.00 \\
(0.41)\end{array}$ & $\begin{array}{l}-0.99 \\
(0.41)\end{array}$ & $\begin{array}{l}-0.90 \\
(0.38)\end{array}$ & $\begin{array}{l}-0.88 \\
(0.38)\end{array}$ & $\begin{array}{l}-0.80 \\
(0.36)\end{array}$ & $\begin{array}{l}-0.89 \\
(0.38)\end{array}$ \\
\hline Liquidity in $\$ 10,000$ s & & $\begin{array}{l}-0.80 \\
(0.26)\end{array}$ & $\begin{array}{l}-0.77 \\
(0.24)\end{array}$ & $\begin{array}{l}-0.76 \\
(0.24)\end{array}$ & & \\
\hline IHS of Liquidity & & & & & $\begin{array}{l}-2.48 \\
(0.66)\end{array}$ & \\
\hline Pctile Rank of Liquidity & & & & & & $\begin{array}{l}-0.37 \\
(0.18)\end{array}$ \\
\hline Impatience & & & $\begin{array}{c}0.20 \\
(0.23)\end{array}$ & $\begin{array}{c}0.03 \\
(0.19)\end{array}$ & $\begin{array}{c}0.03 \\
(0.19)\end{array}$ & $\begin{array}{c}0.04 \\
(0.19)\end{array}$ \\
\hline Present Bias & & & $\begin{array}{c}0.58 \\
(0.38)\end{array}$ & $\begin{array}{c}0.52 \\
(0.38)\end{array}$ & $\begin{array}{c}0.48 \\
(0.38)\end{array}$ & $\begin{array}{c}0.53 \\
(0.39)\end{array}$ \\
\hline Risk Aversion & & & & $\begin{array}{c}0.25 \\
(0.30)\end{array}$ & $\begin{array}{c}0.16 \\
(0.30)\end{array}$ & $\begin{array}{c}0.28 \\
(0.30)\end{array}$ \\
\hline Log Income & $\begin{array}{c}0.37 \\
(0.83)\end{array}$ & $\begin{array}{c}0.98 \\
(0.89)\end{array}$ & $\begin{array}{c}1.08 \\
(0.91)\end{array}$ & $\begin{array}{c}1.13 \\
(0.93)\end{array}$ & $\begin{array}{c}2.59 \\
(1.08)\end{array}$ & $\begin{array}{c}0.65 \\
(0.89)\end{array}$ \\
\hline Years of Schooling & $\begin{array}{l}-0.30 \\
(0.20)\end{array}$ & $\begin{array}{l}-0.27 \\
(0.20)\end{array}$ & $\begin{array}{l}-0.27 \\
(0.20)\end{array}$ & $\begin{array}{l}-0.27 \\
(0.20)\end{array}$ & $\begin{array}{l}-0.09 \\
(0.18)\end{array}$ & $\begin{array}{l}-0.29 \\
(0.20)\end{array}$ \\
\hline Female & $\begin{array}{l}-3.05 \\
(1.85)\end{array}$ & $\begin{array}{l}-3.21 \\
(1.88)\end{array}$ & $\begin{array}{l}-3.60 \\
(2.01)\end{array}$ & $\begin{array}{l}-3.66 \\
(2.01)\end{array}$ & $\begin{array}{l}-3.56 \\
(1.97)\end{array}$ & $\begin{array}{l}-3.51 \\
(1.99)\end{array}$ \\
\hline Age & $\begin{array}{l}-0.04 \\
(0.10)\end{array}$ & $\begin{array}{l}-0.03 \\
(0.10)\end{array}$ & $\begin{array}{l}-0.05 \\
(0.10)\end{array}$ & $\begin{array}{l}-0.06 \\
(0.10)\end{array}$ & $\begin{array}{c}-4.48 \mathrm{E}-03 \\
(0.10)\end{array}$ & $\begin{array}{l}-0.07 \\
(0.10)\end{array}$ \\
\hline $\mathrm{Age}^{2}$ & $\begin{array}{c}-0.01 \\
(4.33 \mathrm{E}-03)\end{array}$ & $\begin{array}{c}-4.42 \mathrm{E}-03 \\
(4.26 \mathrm{E}-03)\end{array}$ & $\begin{array}{c}-4.97 \mathrm{E}-03 \\
(4.19 \mathrm{E}-03)\end{array}$ & $\begin{array}{l}-4.97 \mathrm{E}-03 \\
(4.19 \mathrm{E}-03)\end{array}$ & $\begin{array}{l}-4.79 \mathrm{E}-03 \\
(4.19 \mathrm{E}-03)\end{array}$ & $\begin{array}{c}-0.01 \\
(4.3 \mathrm{E}-03)\end{array}$ \\
\hline $\mathrm{R}^{2}$ & 0.0005 & 0.0006 & 0.0007 & 0.0007 & 0.0014 & 0.0007 \\
\hline
\end{tabular}

Note: This table controls for more flexible forms of liquidity. It shows results from regressions at the individual-daily level. The dependent variable is an indicator for whether participant $i$ took a payday loan on day $d$. We multiplied it by 10,000 so the coefficients can be interpreted as the effect on a hundredth of a percentage point. Its mean is 3.79. Liquidity refers to the liquidity on

${ }^{17}$ Appendix Table 7 presents results that allow for interactive effects of liquidity and decision-making ability at the daily level. Results are qualitatively similar to those in the low-frequency specification of Table 7. By estimating the relationship between payday loan demand and liquidity measured at both individual average and individual daily frequencies, we assess the role of both highly persistent and immediate financial circumstances in the decision to take a high cost loan. In Appendix Table 8, we evaluate a role for intermediate financial circumstances by repeating the analysis in Table 8, but at a monthly frequency. The results are qualitatively similar to those at the daily frequency. 
the previous day, i.e., $d-1$. Columns (2)-(4) include liquidity in levels as a control. Colum (5) controls for the inverse hyperbolic sine of liquidity. Column (6) adds a within-participant percentile rank measure of liquidity. In particular, the liquidity of participant $i$ on day $d-1$ was ranked relative to the liquidity of participant $i$ in all other days in the individual time series of the participant. Decision-making ability, time and risk preferences are measured in percentile ranks divided by 10 , such that the coefficient gives the effect of an increase of the independent variable in 10 percentiles. The regressions include dummies for day of the week and for calendar day of the month. Number of observations $=1,388,959$. Number of participants $=1,573$. Number of days $=883$. Standard errors clustered at the individual level.

\section{The Importance of Prior Mistakes}

A lack of financial resources today could be a consequence of poor decision-making in the past. In this way, earlier "mistakes" may cause "misfortune," which raises concerns about whether the preceding analysis understates the importance of "mistakes." While a test of such a hypothesis is beyond the scope of the paper, we illustrate here that "mistakes" are unlikely to be a primary driver of the "misfortune" as captured by the measures of liquidity in the previous analysis.

\section{Figure 6: Liquidity and Demand for Payday Loans by Day of the Month}

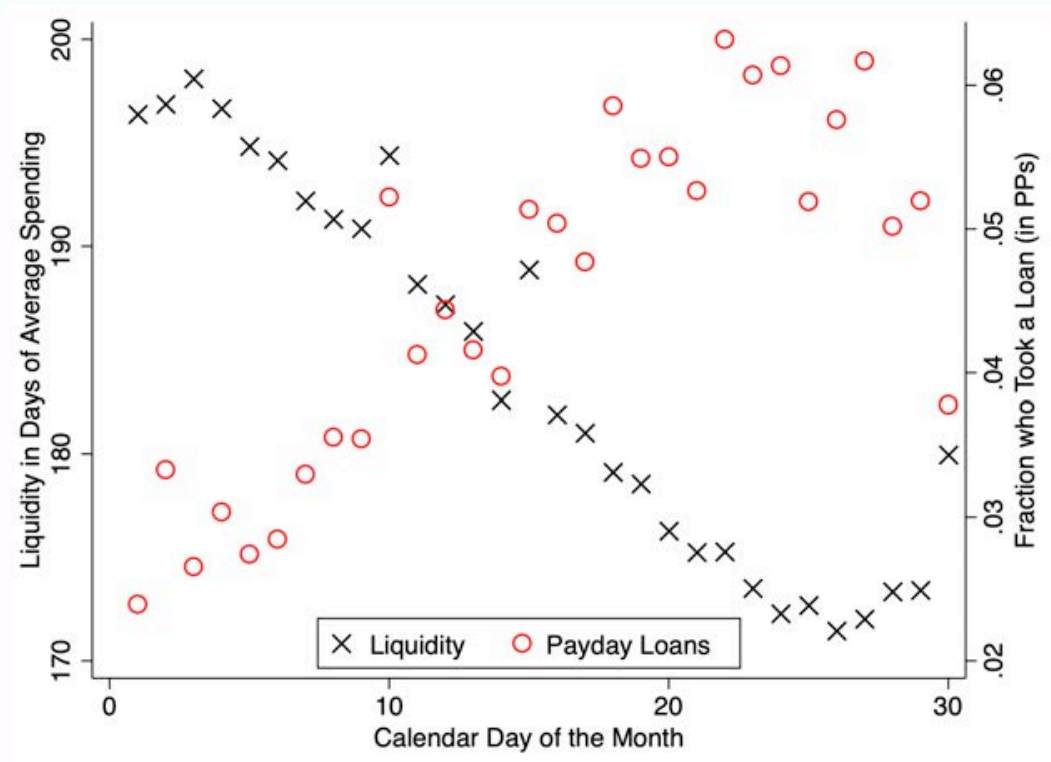

Note: The Xs show in the left y-axis average liquidity - measured in days of average spending - by day of the month. The circles show in the right y-axis the fraction of individuals who took a pay loan by day of the month. Number of liquidity observations $=11,068,083$. Number of payday loan observations $=28,274,836$.

Figure 6 shows, in particular, how average liquidity measured as a fraction of average daily spending evolves over the month (left y-axis). Liquidity is highest in the first four days of the 
month. Thereafter, it starts declining until the $26^{\text {th }}$ when it picks up again. The pattern of the demand for payday loans (right y-axis) mirrors the pattern of liquidity. The demand is low in the first days of the month when liquidity is high, it increases throughout the month as liquidity gradually declines, and it falls in the last days of the month when liquidity bounces back. In this way, factors related to the calendar, and thus presumably unrelated to DMA, seem to induce large and predictable changes in liquidity that are associated with demand for payday loans. These patterns cast doubt on the idea that prior mistakes are a primary driver of the low liquidity that drives demand for payday loans.

In contrast, theories of scarcity (Mullainathan and Shafir, 2013; Carvalho et al. 2016) suggest the importance of mistakes may be overstated. In this view, the many challenges associated with a lack of financial resources may impede cognitive function and degrade the quality of decision-making. If financial scarcity to some extent causes lower decision-making quality, then the regression analyses above will attribute to DMA some of the gross effects of misfortune on payday loan demand.

Figure 7: Decision-Making Ability by Day of the Month in which Participant was Surveyed

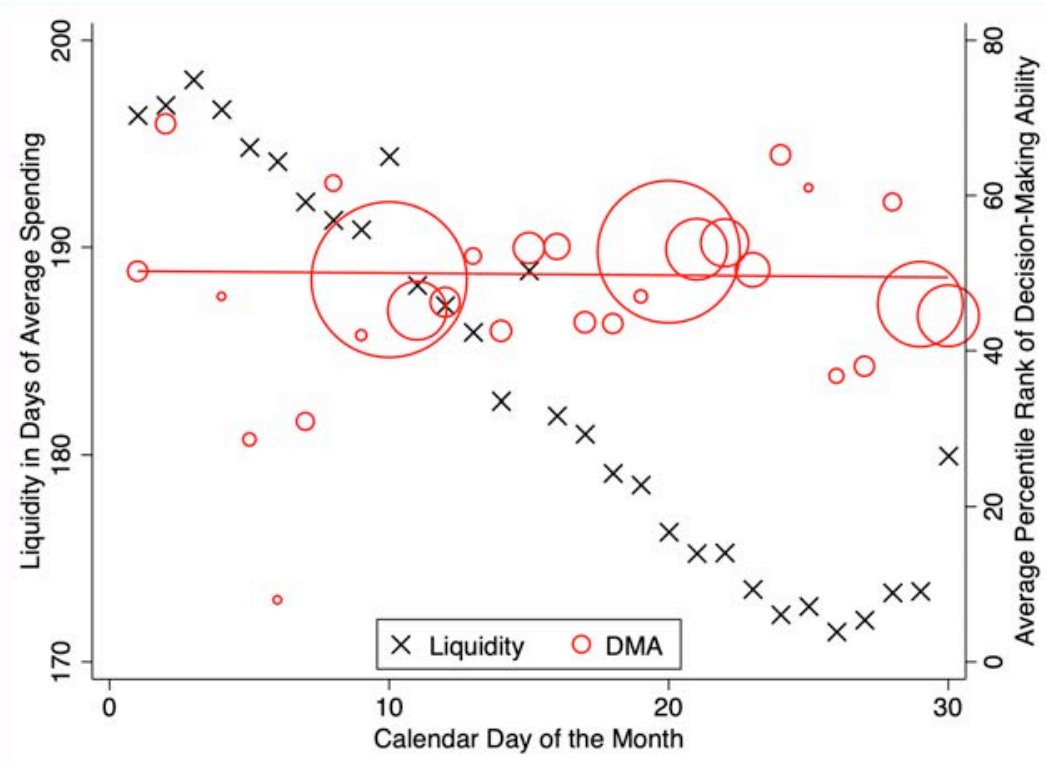

Note: The Xs show in the left y-axis average liquidity - measured in days of average spending - by day of the month. The circles show in the right y-axis average DMA by day of the month. The size of the circumference reflects the number of participants surveyed on that day. Number of liquidity observations $=$ $11,068,083$. Number of DMA observations $=1,728$. 
To evaluate the potential for scarcity effects, Figure 7 presents estimates of how our measure of DMA (right y-axis) varies with the day of the month in which the participant took the survey. The figure also reproduces the pattern of liquidity over the month shown in Figure 6. This analysis provides no evidence of scarcity effects. Those surveyed on especially low-liquidity days exhibit on average the same DMA as those surveyed on higher-liquidity days.

\section{Decision-making Ability and NSF Fees}

The preceding results are consistent with the view that "mistakes" are quantitatively important drivers of demand for payday loans. This interpretation would be misguided, however, if DMA were simply capturing a "type" whose unmeasured constraints, preferences, or beliefs rationalize demand for high-cost loans. It may be, for example, that consistency with utility maximization in the experiment is correlated with unmeasured access to friends or family on whom to rely when misfortune strikes. If so, we would improperly attribute to "mistake" what is actually a lack of access to informal credit.

To evaluate this and related possibilities, we study the relationship between measures of DMA from the experiment and an unambiguous "mistake" in the administrative data: the accrual of non-sufficient funds (NSF) fees. NSF fees are incurred when, in the process of using a debit card to make a purchase, an individual exceeds his or her checking account overdraft limit. The median NSF fee is about $\$ 7.50$ (see Appendix Table 11 for summary statistics). Note this may occur even to an individual who has liquidity in the form of another checking account, a savings account, or a credit card. Different from costly overdrafts in markets like the U.S., there is no benefit to exceeding the limit because the purchase will not be authorized. A choice that results in an NSF fee is dominated by the decision not to try to make the purchase. Like an American looking left (but not right) before crossing the street in the United Kingdom, incurring an NSF fee may be understandable, but would almost universally be viewed as a "mistake." 


\begin{tabular}{|c|c|c|c|c|c|c|}
\hline \multirow[b]{2}{*}{ DMA $*$ Liquidity } & \multicolumn{6}{|c|}{ Number of Non-Sufficient Funds Charges } \\
\hline & & & & & $\begin{array}{c}0.02 \\
(0.03)\end{array}$ & $\begin{array}{c}0.02 \\
(0.03)\end{array}$ \\
\hline DMA & $\begin{array}{l}-0.23 \\
(0.08)\end{array}$ & & $\begin{array}{l}-0.19 \\
(0.08)\end{array}$ & $\begin{array}{l}-0.17 \\
(0.08)\end{array}$ & $\begin{array}{l}-0.19 \\
(0.08)\end{array}$ & $\begin{array}{l}-0.17 \\
(0.08)\end{array}$ \\
\hline Liquidity & & $\begin{array}{l}-0.57 \\
(0.09)\end{array}$ & $\begin{array}{l}-0.55 \\
(0.09)\end{array}$ & $\begin{array}{l}-0.54 \\
(0.09)\end{array}$ & $\begin{array}{l}-0.55 \\
(0.09)\end{array}$ & $\begin{array}{l}-0.54 \\
(0.09)\end{array}$ \\
\hline Impatience & & & & $\begin{array}{l}-0.06 \\
(0.07)\end{array}$ & & $\begin{array}{l}-0.07 \\
(0.07)\end{array}$ \\
\hline Present Bias & & & & $\begin{array}{l}-0.10 \\
(0.08)\end{array}$ & & $\begin{array}{l}-0.10 \\
(0.08)\end{array}$ \\
\hline Risk Aversion & & & & $\begin{array}{c}0.16 \\
(0.08)\end{array}$ & & $\begin{array}{c}0.17 \\
(0.08)\end{array}$ \\
\hline Log Income & $\begin{array}{c}0.22 \\
(0.30)\end{array}$ & $\begin{array}{c}1.04 \\
(0.32)\end{array}$ & $\begin{array}{c}1.07 \\
(0.33)\end{array}$ & $\begin{array}{c}1.10 \\
(0.33)\end{array}$ & $\begin{array}{c}1.08 \\
(0.33)\end{array}$ & $\begin{array}{c}1.11 \\
(0.33)\end{array}$ \\
\hline Years of Schooling & $\begin{array}{l}-0.09 \\
(0.07)\end{array}$ & $\begin{array}{l}-0.04 \\
(0.07)\end{array}$ & $\begin{array}{l}-0.03 \\
(0.07)\end{array}$ & $\begin{array}{l}-0.02 \\
(0.07)\end{array}$ & $\begin{array}{l}-0.03 \\
(0.07)\end{array}$ & $\begin{array}{l}-0.02 \\
(0.07)\end{array}$ \\
\hline Female & $\begin{array}{c}0.04 \\
(0.41)\end{array}$ & $\begin{array}{l}-0.08 \\
(0.40)\end{array}$ & $\begin{array}{l}-0.12 \\
(0.40)\end{array}$ & $\begin{array}{l}-0.16 \\
(0.40)\end{array}$ & $\begin{array}{l}-0.10 \\
(0.39)\end{array}$ & $\begin{array}{l}-0.14 \\
(0.39)\end{array}$ \\
\hline Age & $\begin{array}{c}0.05 \\
(0.02)\end{array}$ & $\begin{array}{c}0.08 \\
(0.02)\end{array}$ & $\begin{array}{c}0.07 \\
(0.02)\end{array}$ & $\begin{array}{c}0.06 \\
(0.02)\end{array}$ & $\begin{array}{c}0.07 \\
(0.02)\end{array}$ & $\begin{array}{c}0.06 \\
(0.02)\end{array}$ \\
\hline $\mathrm{Age}^{2}$ & $\begin{array}{l}-4.70 \mathrm{E}-03 \\
(9.58 \mathrm{E}-04)\end{array}$ & $\begin{array}{l}-3.98 \mathrm{E}-03 \\
(9.24 \mathrm{E}-04)\end{array}$ & $\begin{array}{l}-4.11 \mathrm{E}-03 \\
(9.23 \mathrm{E}-04)\end{array}$ & $\begin{array}{l}-4.08 \mathrm{E}-03 \\
(9.38 \mathrm{E}-04)\end{array}$ & $\begin{array}{c}-4.09 \mathrm{E}-03 \\
(9.28 \mathrm{E}-04)\end{array}$ & $\begin{array}{l}-4.06 \mathrm{E}-03 \\
(9.42 \mathrm{E}-04)\end{array}$ \\
\hline $\mathrm{R}^{2}$ & 0.02 & 0.05 & 0.05 & 0.06 & 0.05 & 0.06 \\
\hline
\end{tabular}

Notes: This table investigates the relationship between non-sufficient funds (NSF) charges, decision-making ability, and liquidity. The mean of the dependent variable is 2.43 . Decision-making ability, liquidity, time preferences and risk preferences are measured in percentile ranks divided by 10 . Number of observations $=1,542$.

The relationship between DMA and NSF fees can thus provide evidence on the validity of using measures of consistency with utility maximization in the experiments as measures of DMA. It can, in particular, inform the hypothesis that it is a correlation with unmeasured constraints, preferences, or beliefs, rather than with DMA, that drives the estimated relationship between consistency with utility maximization and demand for payday loans. If consistency with utility maximization in the experiments largely proxies for unmeasured constraints, preferences, or beliefs that rationalize payday loans, it should not predict the unambiguous "mistake" of NSF fees. 
Table 9 shows that the measure of DMA is indeed predictive of this unambiguous "mistake." A reduction of 10 percentiles in DMA increases the number of NSF charges by 0.170.23 (relative to a base rate of 2.43). Liquidity is also associated with NSF charges: A reduction of 10 percentiles in liquidity increases the number of NSF charges by 0.54-0.57. Interestingly, the interaction between DMA and liquidity is not statistically distinguishable from zero at conventional levels of confidence. Even among those with liquidity, individuals with lower DMA are more likely to engage in this imperfection.

\section{External Relevance: Results from US Survey Data}

The combination of administrative and survey data from Iceland has advantages for studying the relationships between economic circumstances, DMA, and demand for high-cost credit. The administrative data offer high-frequency, accurate measures of economic circumstances and demand for a relatively large, long, and balanced panel. The survey data provide rich measures of preferences and DMA derived from multiple decision domains. One potential concern, though, is that Iceland is a small economy and its people and markets may have distinctive characteristics that limit the external relevance of findings derived from them.

To assess external relevance, we turn to survey data from the U.S. and compare, to the extent possible, the relationships between economic circumstances, DMA, and demand for highcost credit in those data with the analogous evidence from Iceland. The U.S. data are drawn from the Understanding America Study (UAS), an Internet panel with respondents aged 18 and older living in the U.S. ${ }^{18}$ About twice a month, respondents receive an email with a request to visit the UAS site and complete questionnaires. Regular questionnaires collect self-reported economic and demographic information. Two supplementary UAS questionnaires first fielded in 2015 have asked respondents whether they have a payday loan or have had one in the past year. A third survey administered Choi et al.'s (2014) choice under risk experiment. See Appendix for more details.

Combining responses from these three supplements with information from regular UAS questionnaires, we can estimate the relationship between self-reported economic circumstances,

\footnotetext{
${ }^{18}$ Respondents are recruited by address-based sampling. Those without Internet access at the time of recruitment are provided tablets and Internet access.
} 
preferences and DMA as revealed in the choice under risk experiment, ${ }^{19}$ and self-reported demand for this kind of high-cost credit. Table 10 presents the results from the UAS alongside analogous estimates from the Icelandic data.

Table 10: Decision-making Ability and Payday Loan Demand in Iceland and U.S.

\begin{tabular}{|c|c|c|c|c|c|c|c|c|}
\hline & \multicolumn{8}{|c|}{1 if Had Payday Loan } \\
\hline & Iceland & UAS & Iceland & UAS & Iceland & UAS & Iceland & UAS \\
\hline DMA & $\begin{array}{c}-0.41 \\
(0.19)\end{array}$ & $\begin{array}{c}-0.53 \\
(0.11)\end{array}$ & $\begin{array}{l}-0.55 \\
(0.20)\end{array}$ & $\begin{array}{l}-0.55 \\
(0.12)\end{array}$ & $\begin{array}{c}-0.49 \\
(0.20)\end{array}$ & $\begin{array}{c}-0.39 \\
(0.12)\end{array}$ & $\begin{array}{c}-0.36 \\
(0.20)\end{array}$ & $\begin{array}{c}-0.42 \\
(0.11)\end{array}$ \\
\hline Risk Aversion & & & & & & & $\begin{array}{c}0.53 \\
(0.17)\end{array}$ & $\begin{array}{c}0.16 \\
(0.11)\end{array}$ \\
\hline Log Income & & & & & $\begin{array}{c}-0.17 \\
(0.63)\end{array}$ & $\begin{array}{c}-0.68 \\
(0.26)\end{array}$ & $\begin{array}{c}0.01 \\
(0.62)\end{array}$ & $\begin{array}{l}-0.66 \\
(0.26)\end{array}$ \\
\hline Years of Schooling & & & & & $\begin{array}{c}-0.53 \\
(0.19)\end{array}$ & $\begin{array}{l}-0.80 \\
(0.16)\end{array}$ & $\begin{array}{l}-0.50 \\
(0.19)\end{array}$ & $\begin{array}{l}-0.79 \\
(0.16)\end{array}$ \\
\hline Female & & & $\begin{array}{l}-1.31 \\
(1.10)\end{array}$ & $\begin{array}{c}2.47 \\
(0.71)\end{array}$ & $\begin{array}{c}-1.14 \\
(1.13)\end{array}$ & $\begin{array}{c}2.20 \\
(0.71)\end{array}$ & $\begin{array}{l}-1.55 \\
(1.13)\end{array}$ & $\begin{array}{c}2.10 \\
(0.71)\end{array}$ \\
\hline Age & & & $\begin{array}{l}-0.14 \\
(0.05)\end{array}$ & $\begin{array}{l}-0.16 \\
(0.03)\end{array}$ & $\begin{array}{l}-0.14 \\
(0.06)\end{array}$ & $\begin{array}{l}-0.16 \\
(0.03)\end{array}$ & $\begin{array}{c}-0.17 \\
(0.06)\end{array}$ & $\begin{array}{l}-0.16 \\
(0.03)\end{array}$ \\
\hline $\mathrm{Age}^{2}$ & & & $\begin{array}{l}-1.43 \mathrm{E}-03 \\
(2.50 \mathrm{E}-03\end{array}$ & $\begin{array}{l}1.64 \mathrm{E}-04 \\
1.49 \mathrm{E}-03)\end{array}$ & $\begin{array}{l}-3.41 \mathrm{E}-0 \\
(2.80 \mathrm{E}-0\end{array}$ & $\begin{array}{l}-2.07 \mathrm{E}-04 \\
1.49 \mathrm{E}-03)\end{array}$ & $\begin{array}{r}-3.60 \mathrm{E}-0 \\
(2.8 \mathrm{E}-03\end{array}$ & $\begin{array}{l}-1.93 \mathrm{E}-04 \\
(1.49 \mathrm{E}-03)\end{array}$ \\
\hline $\mathrm{R}^{2}$ & 0.003 & 0.005 & 0.010 & 0.019 & 0.017 & 0.030 & 0.024 & 0.030 \\
\hline
\end{tabular}

Notes: This table compares the relationship between decision-making ability and payday loan demand in U.S. data from the Understanding America Study (UAS) with the analogous evidence from Iceland. The dependent variable in the former is an indicator variable for whether the participant had had a payday loan in the past year. In the latter, the dependent variable is an indicator for whether the participant had a payday loan during a 6-year period. The dependent variables were multiplied by 100 , such that the coefficients are in percentage points. The mean of the dependent variable is 4.89 in Iceland and 5.05 in the UAS. Decision-making ability and risk aversion are measured in percentile ranks divided by 10 , such that the coefficient gives the effect of increasing decision-making ability or risk aversion in 10 percentiles. For example, the coefficient in the first column implies that an increase in decision-making ability in 10 percentiles is associated with a reduction in 0.41 percentage points in the probability of having a payday loan. In Iceland, the number of participants is 1,573. The UAS data is longitudinal with two waves. The number of observations is 5,243 and the number of participants is 2,954 (not all participants were surveyed in both waves). Standard errors are clustered at the individual level in the UAS. Robust standard errors are estimated for Iceland.

The point estimates are similar in the Icelandic and U.S. data. The unconditional correlation between the percentile rank of the DMA distribution and the probability of taking a loan is -0.41

${ }^{19}$ Derived just from the risk experiment, we are limited in the UAS to measuring preferences with risk tolerance and decision-making ability with consistency with maximization of a utility function that satisfies a dominance principle. 
in Iceland and -0.53 in the US data. Conditioning on several economic and demographic variables, and on a measure of risk aversion, brings the point estimate in the Icelandic data to -0.36 and to 0.42 in the U.S. data. Coefficients on the other variables are qualitatively similar in the two data sets, with the exception of gender. In the US, women are approximately two percentage points more likely to report they have or have had a payday loan while the (relatively imprecise) point estimate in Iceland is approximately -1.3. Taken together, we view the similarities of the two sets of estimates as evidence of the external relevance of the richer set of results derived from the Icelandic data.

\section{Conclusion}

Motivated by the debate on regulation of the high-cost credit market, this paper evaluated the relationship between adverse financial conditions ("misfortune"), imperfect decision-making ("mistakes"), and the demand for high-cost credit. The policy debate revolves around efforts to restrict the circumstances under which individuals may obtain high-cost credit, and the possibility that many choices to take such loans are imperfect. Advocates of regulation see high-cost credit as too often exploiting unsophisticated borrowers who would be better off without the loans. Opponents of the regulation see this form of credit as serving those who are in acute need of liquidity and who find it difficult to obtain elsewhere.

Advancing the debate is difficult in part because "mistakes" are typically hard to identify. Unobserved constraints, preferences, or beliefs can justify many behaviors as optimal, including the demand for high-cost credit. We addressed this identification problem by combining highquality administrative and experimental data from Iceland. The administrative data describe in detail the financial conditions and behaviors associated with high-cost loan demand. In the experimental data, we manipulated constraints while holding preferences and beliefs constant, which allowed us to identify choice imperfections that provide a measure of decision-making ability (DMA).

Evidence from the administrative data alone suggest a substantial but not a dominant role for "mistake" in driving demand for payday loans. Approximately $25 \%$ of payday borrowers have a substantial amount of cheaper credit available when they take the loan. Analysis of spending patterns around the time that loans are taken provides no evidence of financial crisis or special 
deprivation, and at least a small fraction of the loans are spent on seemingly inessential items. These are likely, however, conservative tests of "mistakes" as payday loans may still not be best for those without cheaper forms of credit, and due to data limitations, the spending results may understate the amount going to non-urgent categories of spending.

We therefore related high-cost loan demand to measures of DMA along with measures of constraints and preferences. The results show that payday borrowers exhibit substantially lower DMA in the experiments; $29 \%$ of payday loan dollars are lent to the bottom $10 \%$ of the DMA distribution, and $45 \%$ are lent to the bottom $20 \%$.

In a regression framework, the relationship between DMA and high-cost loan demand is not explained by demographic characteristics, economic circumstances, or measures of preferences from the experiment, and is mirrored by the relationship between DMA and an unambiguous "mistake," the accrual of not sufficient fund fees. The external relevance of the Iceland findings is supported by results from a survey of U.S. consumers where the relationship between DMA and the probability of receiving a payday loan is very similar.

Taken together, the results of this study indicate that both "misfortune" and "mistake" are important for high-cost loan demand. It follows that policy may be justified if it works to address market imperfections that make this credit market incomplete, or if it better equips consumers to avoid any harm from mistakenly choosing to take a high-cost loan. More specifically, given the importance of both "misfortune" and "mistake" implied by these results, efforts at consumer protection should seek ways to avoid limiting trade in this market entirely. The results suggest, instead, that regulators ought to consider lighter forms of paternalism (Loewenstein and Haisley, 2008) like cooling off periods or certification that the borrower understands a loan's terms, to help consumers avoid "mistakes" while still allowing liquidity to flow to those who need it most. 


\section{References}

Afriat, Sydney. "The Construction of a Utility Function from Expenditure Data." Econometrica, 6 (1967), 67-77.

Agarwal, Sumit, Paige Marta Skiba, and Jeremy Tobacman. "Payday Loans and Credit Cards: New Liquidity and Credit Scoring Puzzles?" American Economic Review Papers \& Proceedings, 99(2), 2009, 412-17.

Andersson, Ola, Håkan J. Holm, Jean-Robert Tyran, and Erik Wengström. "Risk Aversion Relates to Cognitive Ability: Preferences or Noise?" Journal of the European Economic Association, 14 (5) (2016), 1129-1154.

Baker, Scott, "Debt and the Consumption Response to Household Income Shocks: Validation and Application of Linked Financial Account Data." Journal of Political Economy 126(4) (2018), 1504, 1557.

Banks, James, Leandro S. Carvalho, and Francisco Perez-Arce. "Education, Decision Making, and Economic Rationality." Review of Economics and Statistics 101(3) (2019): 428-441.

Barsky, Robert B., F. Thomas Juster, Miles S. Kimball, and Matthew D. Shapiro. "Preference Parameters and Behavioral Heterogeneity: An Experimental Approach in the Health and Retirement Study," The Quarterly Journal of Economics, 112(2) (1997), 537-579.

Bertrand, Marianne and Adair Morse, "Information Disclosure, Cognitive Biases, and Payday Borrowing." Journal of Finance, 66(6) (2011), 1865-1893.

Bhutta, Neil, Jacob Goldin, and Tatiana Homonoff, "Consumer Borrowing after Payday Loan Bans." Journal of Law and Economics. 59(1) (2016), 225-259.

Bhutta, Neil, Paige Marta Skiba, and Jeremy Tobacman, "Payday Loan Choices and Consequences." Journal of Money, Credit, and Banking, 47(2-3), 2015, 223-260.

Carlin, Bruce, Arna Olafsson, and Michaela Pagel, "Generational Differences in Managing Personal Finances.” AEA Papers and Proceedings, 109 (2019), 54-59.

Carrell, Scott, and Jonathan Zinman, "In Harm's Way? Payday Loan Access and Military Personnel Performance," The Review of Financial Studies, 27(9) (2014), 2805-2840.

Carvalho, Leandro S., Stephan Meier, and Stephanie W. Wang, "Poverty and Economic Decision-Making: Evidence from Changes in Financial Resources at Payday," American Economic Review, 106(2) (2016): 260-84.

Carvalho, Leandro, and Dan Silverman, "Complexity and Sophistication.” NBER Working Paper, July, 2019.

Central Bank of Iceland, "Financial Stability,” Technical Report, April 2018.

Choi, Syngjoo, Shachar Kariv, Wieland Müller, and Dan Silverman "Who Is (More) Rational?” 
American Economic Review, 104(6) (2014), 1518-50.

Dean, Mark, and Daniel Martin. "Measuring rationality with the minimum cost of revealed preference violations." Review of Economics and Statistics 98(3) (2016): 524-534.

Dobridge, Christine (2016), "For Better and For Worse: Effects of Access to High-Cost Consumer Credit.” Federal Reserve Board Discussion Paper number 2016-056.

Echenique, Federico, Taisuke Imai, and Kota Sato, "Approximate Expected Utility Rationalization," Working Paper (2019).

Epper, Thomas, Ernst Fehr, Helga Fehr-Duda, Claus Thustrup Kreiner, David Dryer Lassen, Søren Leth-Petersen, and Gregers Nytoft Rasmussen, "Time Discounting and Wealth Inequality." Working paper, University of Zurich.

Gathergood, John, Benedict Guttman-Kenney, Stefan Hunt, "How Do Payday Loans Affect Borrowers? Evidence from the U.K. Market," The Review of Financial Studies, 3(2) (2019), 496-523.

Gelman, Michael, Shachar Kariv, Matthew D. Shapiro, Dan Silverman and Steven Tadelis. "Harnessing Naturally Occurring Data to Measure the Response of Spending to Income," Science 345(6193) (2014), 212-215.

, Shachar Kariv, Matthew D. Shapiro, Dan Silverman and Steven Tadelis. 2016. "How Individuals Respond to a Liquidity Shock: Evidence from the 2013 Government Shutdown." Journal of Public Economics. (2018).

Gilboa, Itzhak, Rational Choice. MIT Press, Cambridge, Massachusetts (2012).

Gillen, Ben, Erik Snowberg, and Leeat Yariv, "Experimenting with Measurement Error: Techniques with Applications to the Caltech Cohort Study," Journal of Political Economy, 127 (4) (2019), 1826-1863.

Halevy, Yoram, Dotan Persitz, and Lanny Zrill, "Parametric Recoverability of Preferences," Journal of Political Economy, 126 (4) (2018), 1558-1593.

Hundtofte, Sean, Arna Olafsson, and Michaela Pagel, "Credit Smoothing." Working paper, (2019b).

Kariv, Shachar, and Dan Silverman, "An Old Measure of Decision-Making Quality Sheds New Light on Paternalism," Journal of Institutional and Theoretical Economics, 169 (1) (2013), 29-44.

Kim, Hyuncheol Bryant, Syngjoo Choi, Booyuel Kim, and Cristian Pop-Eleches. "The role of education interventions in improving economic rationality." Science 362(6410) (2018): 83-86.

Kristjánsdóttir, Fanndís Ösp, “Tilurð smálánafyrirtækja - Samanburður við ná- grannalöndin,” Master’s thesis, University of Iceland (2013). Starfsumhverfi smálánafyrirtækja á Íslandi 
Kueng, Lorenz, "Excess Sensitivity of High-Income Consumers." Quarterly Journal of Economics, Vol. 133 (2018): 1693-1751.

Loewenstein, G. \& Haisley, E. (2008). "The Economist As Therapist: Methodological Issues

Raised by "Light" Paternalism." In A. Caplin and A. Schotter (Eds.), "Foundations of Positive and Normative Economics," volume 1 in the Handbook of Economic Methodologies, Oxford, England: Oxford University Press.

Meier, Stephan, and Charles Sprenger. "Present-biased Preferences and Credit Card Borrowing," American Economic Journal: Applied Economics, 2(1) (2010), 193-210.

Melzer, Brian, "The Real Costs of Credit Access: Evidence from the Payday Lending Market," Quarterly Journal of Economics, 126(1) (2011), 517-555.

, "Spillovers from Costly Credit," Review of Financial Studies, 31(9), (2018), 3568-3594.

Morse, Adair. “Payday Lenders: Heroes or Villains?” Journal of Financial Economics, 102(1) (2011), 28-44.

Mullainathan, Sendhil, and Eldar Shafir. (2013). Scarcity: Why Having Too Little Means So Much. New York: Times Books.

Olafsson, Arna and Michaela Pagel, "The liquid hand-to-mouth: Evidence from a personal finance management software." The Review of Financial Studies, 31(11) (2018), 4398-4446.

Polisson, Matthew, John K-H. Quah, and Ludovic Renou. "Revealed Preferences Over Risk and Uncertainty." Working Paper, (2019).

Schmall, Theresa, and Eva Wolkowitz "2016 Financially Underserved Market Size Study," Center for Financial Services Innovation. (2016).

Stango, Victor, and Jonathan Zinman, "We Are All Behavioral, More or Less: Measuring and Using Consumer-level Behavioral Summary Statistics.” Working Paper (2019).

von Gaudecker, Hans-Martin, Arthur van Soest, and Erik Wengström. "Heterogeneity in Risky Choice Behaviour in a Broad Population." American Economic Review, 101(2) (2011): 664-694.

Zinman, Jonathan, "Restricting Consumer Credit Access: Household Survey Evidence on Effects Around the Oregon Rate Cap." Journal of Banking and Finance 34(3) (2010), 546-556. 


\section{APPENDIX \\ For Online Publication}

Examples of Recent Payday Loan Contracts in Iceland

\section{Figure A1: Recent Payday Loan Contract}

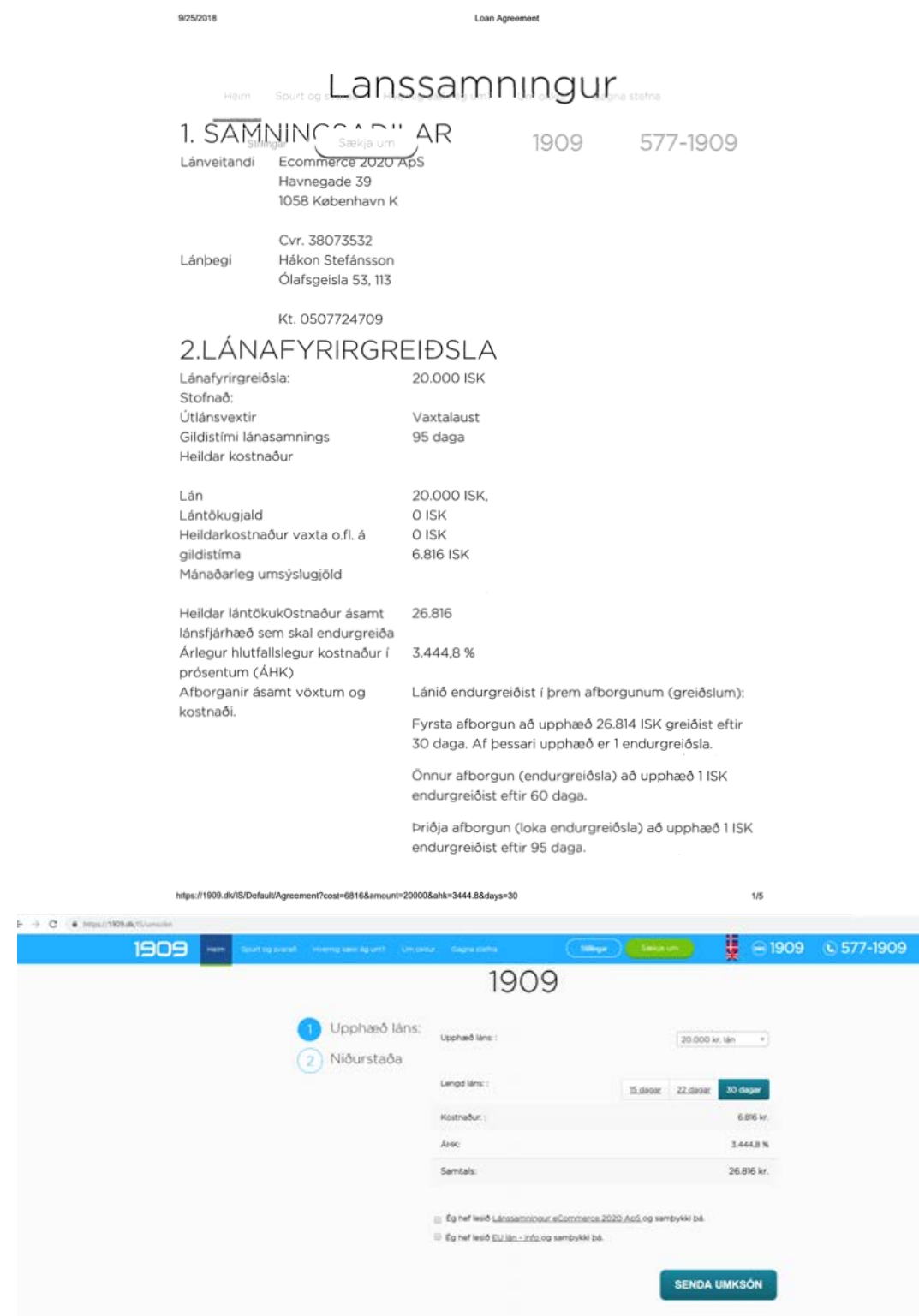

Note: A screen shot of an Iceland payday loan contract and associated user interface from 2018. The loan is for 20,000 ISK (approximately \$200) with a term of 30 days. The finance charge is 6,816 ISK (approximately \$68) which, as declared on the contract and user interface amounts to an APR of 3,444.8\%. Source: Starfsumhverfi smálánafyrirtækja á Íslandi, The Ministry of Tourism, Industry and Innovation, January (2019). 


\section{Time Event Study}

We first restricted the sample to participants who received a payday loan between October 1, 2014 and January 14, 2017 to ensure we could observe liquidity in the 30 days before loans taken on October 1, 2014 and liquidity in the 30 days after loans taken on January 14, 2017.

First, we "detrended" participants' time series of liquidity, controlling for day-of-the-week and calendar-day-of-the-month effects. In particular, using the entire time series of those participants (from September 1, 2014 to February 13, 2017), we ran a regression of liquidity on individualspecific fixed effects, dummies for day of the week, and dummies for calendar day of the month (Monday and the first of the month were the omitted categories). Our main outcome of interest is the residual from this regression, $\hat{u}_{i t}$, where $i$ indexes the participant and $t$ the day. To recover the levels, we added the raw average liquidity, $\hat{\mu}$, to $\hat{u}_{i t}$.

Let $\operatorname{Loan}_{i t}$ be equal to 1 if participant $i$ received a loan on day $t$ and 0 otherwise. In a second step, we restricted the sample to participant-days that fell up to 30 days before or up to 30 days after the participant received a loan:

$$
\left\{i \tau \mid \operatorname{Loan}_{i \tau-30}=1 \text { or } \operatorname{Loan}_{i \tau-29}=1 \text { or } \cdots \text { or } \operatorname{Loan}_{i \tau+29}=1 \text { or } \operatorname{Loan}_{i \tau+30}=1\right\}
$$

Finally, we ran the following regression for Figure 1:

$$
\hat{u}_{i t}+\hat{\mu}=\alpha+\sum_{k=0}^{30} \beta_{k} \text { Before }_{i t}^{k}+\sum_{k=1}^{30} \gamma_{k} \text { After }_{i t}^{k}+\varepsilon_{i t}
$$

where Before $e_{i t}^{k}$ is equal to 1 if participant $i$ took a loan on $t+k$ (and 0 otherwise). Similarly, After ${ }_{i t}^{k}$ is equal to 1 if participant $i$ took a loan on $t-k$ (and 0 otherwise).

We used the same approach for Figure 2. The only differences are that (1) we restricted the sample to loans who followed a period of 31 days or more without loans and (2) the right-hand size of the estimating equation was:

$$
\alpha+\sum_{k=0}^{30} \beta_{k} \text { Before }_{i t}^{k}+\varepsilon_{i t}
$$




\section{Understanding America Study}

The Understanding America Study (UAS) is an Internet panel with respondents aged 18 and older living in the U.S. ${ }^{20}$ About twice a month, respondents receive an email with a request to visit the UAS site and complete questionnaires.

In UAS survey modules 18 and 119, participants were asked the following question:

Payday loans are small, short-term loans that must be paid in full when the borrowers receive their next pay check or other regular deposit (such as a Social Security payment). These loans are often paid with a post-dated check. Please select the following statement that best describes your situation regarding these products.

1 I have never considered getting a payday loan from a payday lender

2 I currently have a payday loan

3 I have had a payday loan in the past year

4 I currently have a payday loan and I have had one in the past year

5 I considered getting a payday loan but was rejected

6 I have considered getting a payday loan but decided not to get it

We coded those that answered (2), (3), and (4) as having had a payday loan.

In UAS survey module 5, participants were administered Choi et al. (2014)'s risk choice experiment. Each participant made 25 choices. There were ten different sets, each with 25 budget lines. Participants were randomly assigned to one of these sets. The measure of decision-making ability is a unified measure of violations of GARP and FOSD - as with these participants in Iceland who did not have the outside option. We calculated the percentile rank of decision-making ability, separately for each one of the ten sets. We also used the choices from the risk choice experiment to calculate risk aversion, following the same procedure described in the paper (with the exception that in this case we used all 25 budget lines).

The demographic information (i.e., gender and age) and the information about education (which was converted from highest degree to years of schooling) come from the "my household" survey module that is administered on a quarterly basis. The information on total household income comes from a survey module (in particular survey module 24) based on the 2014 wave of the Health and Retirement Study (HRS) that was administered to all UAS participants.

\footnotetext{
${ }^{20}$ Respondents are recruited by address-based sampling. Those without Internet access at the time of recruitment are provided tablets and Internet access.
} 


\section{Experimental Tasks}

Risk Task

Participants allocated an experimental endowment of $500 \mathrm{kr}$. (appr. \$5) across two or five assets. The assets paid different amounts depending on whether on whether a ball drawn from an urn was black or white. Participants were informed that the urn had five black balls and five white balls. Their decisions involved choosing how much to invest on each asset. Participants were presented with 15 investment problems (one of the 15 problems was randomly selected for payment). We varied the asset returns across the investment problems.

In the first eight investment problems, there were two assets. In the last seven investment problems, there were five assets. This design, which follows Carvalho \& Silverman (2019), permits identifying the effects of complexity on each participant.

Appendix Figure 1 shows a screenshot of the interface for problems with two assets. The table at the top of the screen shows the returns of assets A and B per $1 \mathrm{kr}$. invested. The participant was then prompted to make her investment choices. The graph below the table displays two bars: the first bar shows the amount invested on asset A; the second bar shows the amount invested on asset B. Participants made their investments by either dragging the bars up and down or by clicking on the + and - buttons. ${ }^{21}$ We originally included negative contingent returns in order to be able to estimate loss aversion. Participants were given a show up fee of $800 \mathrm{kr}$. or more to ensure that the show up fee plus the earnings in all three tasks would be positive. ${ }^{22}$

\footnotetext{
${ }^{21}$ The interface was such that participants always invested $100 \%$ of their experimental endowment.

${ }^{22}$ Some participants were randomly assigned to have a show up fee of $4,000 \mathrm{kr}$.
} 


\section{Appendix Figure 1: Interface Risk Task with Two Assets and without Outside Option}

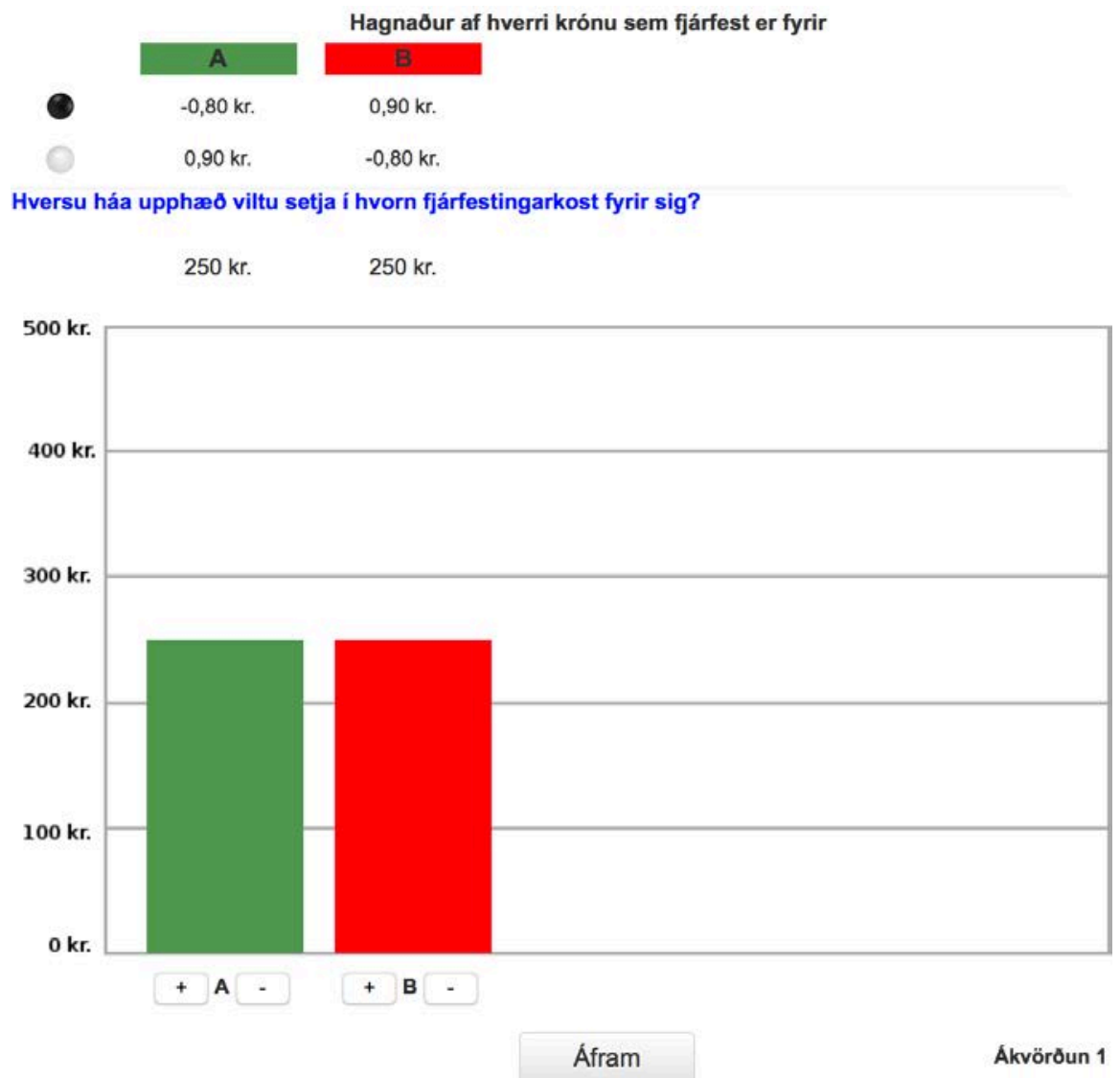

Note: This figure shows the interface participants without the outside option used to make investment choices in the risk task when two assets were available (i.e., choices 1-8). That is also the interface that all participants used to make their investment choices in the ambiguity task.

Appendix Figure 2 shows that a similar interface was used in the investment problems with five assets. The only distinction is that they were shown information about 5 assets $-\mathrm{A}, \mathrm{B}, \mathrm{C}, \mathrm{D}$, and $\mathrm{E}-$ and the graph displayed 5 bars. 


\section{Appendix Figure 2: Interface Risk Task with Five Assets and without Outside Option}

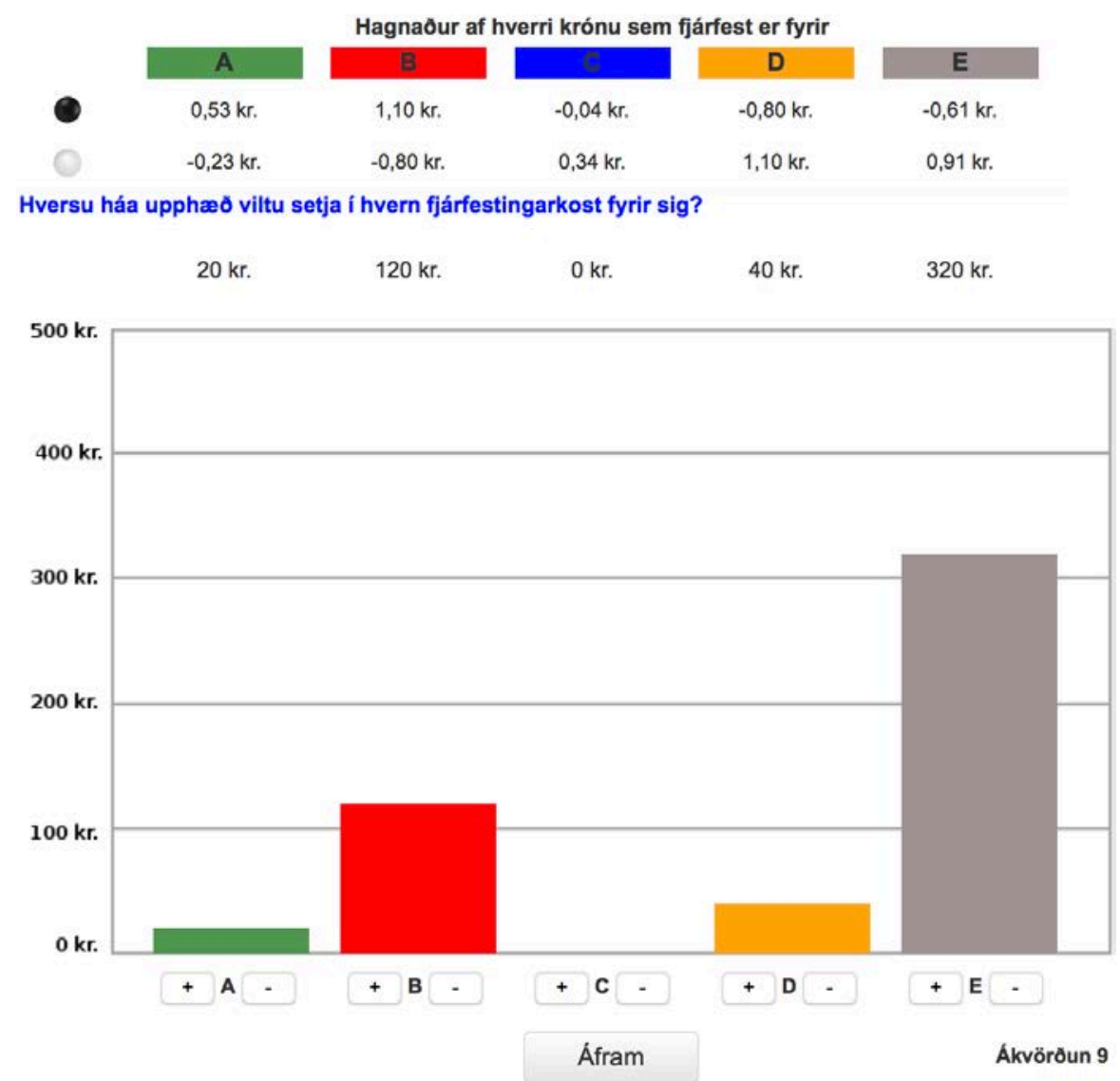

Note: This figure shows the interface participants without the outside option used to make investment choices in the risk task when five assets were available (i.e., choices 9-15).

In order to study choice avoidance, half of the participants were randomly assigned to be offered the option of avoiding the investment problem (Carvalho \& Silverman 2019). In particular, these participants were offered the choice between making the investment decision or taking an outside option of $-50 \mathrm{kr}$., $0 \mathrm{kr}$., or $100 \mathrm{kr}$. The amount of the outside option was varied across the investment problems. The participant was paid the outside option if in the problem selected for payment she chose to avoid. Appendix Table 1 shows the parameters of the 15 decision problems. 
Appendix Table 1: Parameters Risk Task

\begin{tabular}{|c|c|c|c|c|c|c|c|c|c|c|c|}
\hline & \multirow{2}{*}{$\begin{array}{l}\text { Outside } \\
\text { Option }\end{array}$} & \multicolumn{2}{|c|}{$\mathbf{A}$} & \multicolumn{2}{|c|}{ B } & \multicolumn{2}{|c|}{ C } & \multicolumn{2}{|c|}{ D } & \multicolumn{2}{|c|}{$\mathbf{E}$} \\
\hline & & Heads & Tails & Heads & Tails & Heads & Tails & Heads & Tails & Heads & Tails \\
\hline 1 & 100 & -0.80 & 0.90 & 0.90 & -0.80 & & & & & & \\
\hline 2 & -50 & 0.95 & -0.80 & -0.80 & 1.13 & & & & & & \\
\hline 3 & -50 & 0.70 & -0.80 & -0.80 & 1.20 & & & & & & \\
\hline 4 & 100 & -0.80 & 0.35 & 1.50 & -0.80 & & & & & & \\
\hline 5 & -50 & -0.80 & 0.45 & 1.40 & -0.80 & & & & & & \\
\hline 6 & 100 & -0.80 & 0.80 & 1.20 & -0.80 & & & & & & \\
\hline 7 & 0 & 0.46 & -0.80 & -0.80 & 1.30 & & & & & & \\
\hline 8 & 0 & -0.80 & 0.60 & 1.30 & -0.80 & & & & & & \\
\hline 9 & 0 & 0.53 & -0.23 & 1.10 & -0.80 & -0.04 & 0.34 & -0.80 & 1.10 & -0.61 & 0.91 \\
\hline 10 & 100 & -0.80 & 1.60 & -0.71 & 1.36 & 0.10 & -0.80 & -0.17 & -0.08 & -0.44 & 0.64 \\
\hline 11 & 0 & -0.55 & 0.10 & 0.20 & -0.20 & 0.95 & -0.50 & 1.70 & -0.80 & -0.80 & 0.20 \\
\hline 12 & -50 & -0.69 & 1.18 & -0.36 & 0.52 & -0.03 & -0.14 & 0.30 & -0.80 & -0.80 & 1.40 \\
\hline 13 & -50 & -0.20 & 0.40 & -0.80 & 1.20 & -0.65 & 1.00 & 0.70 & -0.80 & 0.25 & -0.20 \\
\hline 14 & 100 & -0.60 & 0.64 & 0.60 & -0.32 & 0.00 & 0.16 & -0.80 & 0.80 & 1.20 & -0.80 \\
\hline 15 & 0 & 1.30 & -0.80 & -0.80 & 0.60 & -0.59 & 0.46 & 0.04 & 0.04 & 0.67 & -0.38 \\
\hline
\end{tabular}

Note: This table shows the parameters of the 15 decisions in the risk task. The first column shows the outside option. The other columns show for each asset the return per $1 \mathrm{kr}$. invested depending on the outcome of the coin toss.

Appendix Figure 3A and Appendix Figure 3B show screenshots of the interfaces used by participants with the outside option. It differs from the interface used by other participants (Appendix Figure 1 and Appendix Figure 2) in two ways. First, the graph with the bars is not shown. Second, the prompt to invest ("You will choose the amount you want to invest on each asset.") is replaced by a prompt for the participant to choose between investing the experimental endowment (button "Invest Y kr.") and taking the outside option (button "Receive X kr."). If she clicked on the first button, the bars were unveiled and she could make her investment choices using the same interface used by other participants. If she clicked on the second button, she was presented with the next decision problem. 


\section{Appendix Figure 3A: Interface Risk Task with Two Assets and with Outside Option Hagnaøur af hverri krónu sem fjárfest er fyrir

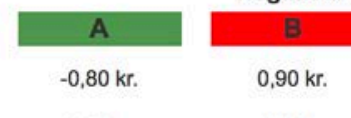 \\ $0,90 \mathrm{kr} . \quad-0,80 \mathrm{kr}$. \\ Hvort kýst pú aô: Fjárfesta fyrir 500 kr. Fá greiddar 100 kr.}

Note: This figure shows the screen in which participants with the outside option were prompted to choose between investing in two assets and taking the outside option (in this example $100 \mathrm{kr}$.). If the participant chose to invest, s/he used the interface shown in Appendix Figure 1 to make her investment choices. If $\mathrm{s} / \mathrm{he}$ chose the outside option, she would move to the next decision (in this example move from decision 1 to decision 2). 


\title{
Appendix Figure 3B: Interface Risk Task with Five Assets and with Outside Option
}

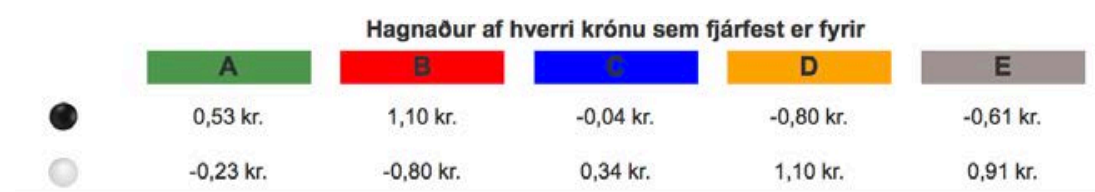

Hvort kýst bú aô: Fjárfesta fyrir 500 kr. Fá greiddar 0 kr.

\begin{abstract}
Ákvörơun 9
Note: This figure shows the screen in which participants with the outside option were prompted to choose between investing in five assets and taking the outside option (in this example $0 \mathrm{kr}$.). If the participant chose to invest, s/he used the interface shown in Appendix Figure 2 to make her investment choices. If s/he chose the outside option, she would move to the next decision (in this example move from decision 9 to decision $10)$.
\end{abstract}




\section{Ambiguity Task}

The ambiguity task was similar to the risk task with three distinctions. First, participants were informed that the urn now had eight balls of one color and two balls of the other color. However, they did not know whether the urn had eight black balls and two white balls or if it had two black balls and eight white balls. Second, in all 15 investment problems there were just two assets. Third, participants were not offered the option of avoiding the investment problem. Appendix Table 2 shows the parameters of the 15 investment problems. As in the risk task, one of the 15 problems was randomly selected for payment.

We had a slightly different research idea at the time of the data collection that required having measures of ambiguity aversion. Hence why we administered the ambiguity task. We think there is no clear prediction as to how ambiguity aversion may affect the demand for payday loans so we opted for excluding ambiguity aversion from the analyses reported in this paper.

\section{Appendix Table 2: Parameters Ambiguity Task}

A

B

\begin{tabular}{cccccc} 
& Heads & Tails & & Heads & Tails \\
\cline { 2 - 3 } \cline { 6 - 6 } 1 & -0.80 & 0.90 & & 0.90 & -0.80 \\
2 & 0.95 & -0.80 & & -0.80 & 1.13 \\
3 & 0.70 & -0.80 & & -0.80 & 1.20 \\
4 & -0.80 & 0.35 & & 1.50 & -0.80 \\
5 & -0.80 & 0.45 & & 1.40 & -0.80 \\
6 & -0.80 & 0.80 & & 1.20 & -0.80 \\
7 & 0.46 & -0.80 & & -0.80 & 1.30 \\
8 & -0.80 & 0.60 & & 1.30 & -0.80 \\
9 & 1.10 & -0.80 & & -0.80 & 1.10 \\
10 & 0.10 & -0.80 & & -0.80 & 1.60 \\
11 & -0.80 & 0.20 & & 1.70 & -0.80 \\
12 & -0.80 & 1.40 & & 0.30 & -0.80 \\
13 & 1.14 & -0.80 & & -0.80 & 0.96 \\
14 & 0.19 & -0.80 & & -0.80 & 1.50 \\
15 & 1.60 & -0.80 & & -0.80 & 0.27
\end{tabular}

Note: This table shows the parameters of the 15 decisions in the ambiguity task. It shows for assets A and B the return per $1 \mathrm{kr}$. invested depending on the outcome of the coin toss. 


\section{Intertemporal Choice Task}

Participants had to allocate their experimental endowment across a sooner date and a later date. The amount allocated to the later date accrued an experimental interest rate. Participants were presented with 12 intertemporal allocation problems (one of the 12 problems was randomly selected for payment). We varied the experimental endowment, the experimental interest rate, and the sooner date across the problems. In the first six problems, the sooner date was today. In the last six problems, the sooner date was one year away. The time interval between the sooner and later dates was always one month. Within a time frame, the interest rate increased monotonically. Appendix Table 3 shows the parameters of the 12 intertemporal allocation problems.

Appendix Figure 4 shows a screenshot of the interface participants used in the intertemporal allocation task. Two calendar sheets at the top of the screen show the sooner date (calendar sheet on the left) and the later date (calendar sheet on the right). The graph below the calendar sheets displays two bars: the bar on the left shows the amount to be received at the sooner date; the bar on the right shows the amount to be received at the later date (including the interest accrued). Participants made their intertemporal allocations by either dragging the bars up and down or by clicking on the + and - buttons. ${ }^{23}$

\footnotetext{
${ }^{23}$ The interface was such that participants always invested $100 \%$ of their experimental endowment.
} 


\section{Appendix Figure 4: Intertemporal Choice Task}

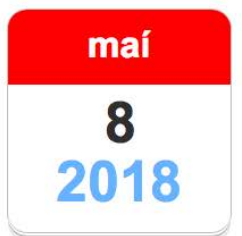

$250 \mathrm{kr}$

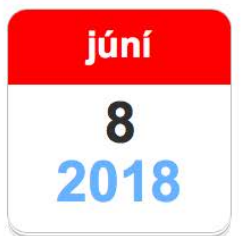

$285 \mathrm{kr}$.

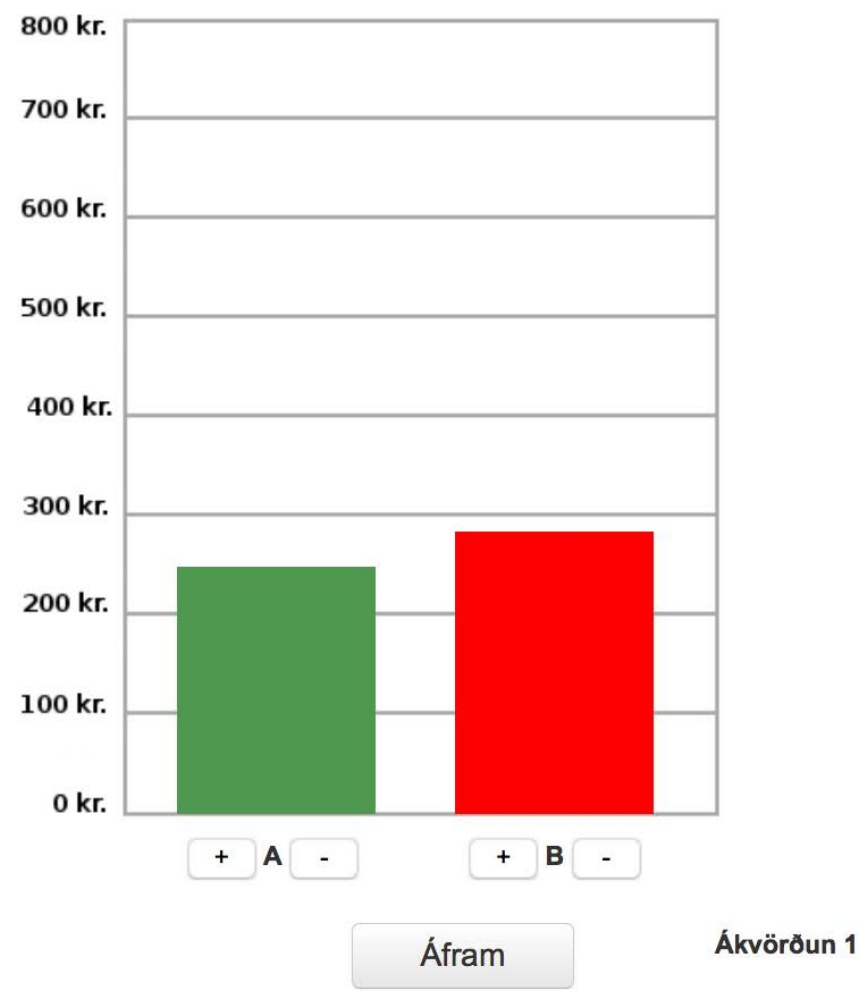

Note: This figure shows the interface participants used to make their intertemporal choices. The calendar on the left showed the earlier date. The calendar on the right showed the later date. The green bar on the left showed the amount received sooner. The red bar on the right showed the amount received later. 


\section{Appendix Table 3: Parameters Intertemporal Choice Task}

\begin{tabular}{|c|c|c|c|c|}
\hline & Sooner & Later & Endowment & Interest Rate \\
\hline 1 & Today & In 1 Month & 550 & $-5 \%$ \\
\hline 2 & Today & In 1 Month & 550 & $10 \%$ \\
\hline 3 & Today & In 1 Month & 475 & $25 \%$ \\
\hline 4 & Today & In 1 Month & 475 & $50 \%$ \\
\hline 5 & Today & In 1 Month & 400 & $75 \%$ \\
\hline 6 & Today & In 1 Month & 350 & $125 \%$ \\
\hline 7 & In 12 Months & In 13 Months & 550 & $-5 \%$ \\
\hline 8 & In 12 Months & In 13 Months & 550 & $10 \%$ \\
\hline 9 & In 12 Months & In 13 Months & 475 & $25 \%$ \\
\hline 10 & In 12 Months & In 13 Months & 475 & $50 \%$ \\
\hline 11 & In 12 Months & In 13 Months & 400 & $75 \%$ \\
\hline 12 & In 12 Months & In 13 Months & 350 & $125 \%$ \\
\hline
\end{tabular}

Note: This table shows the parameters of the 12 decisions in the intertemporal choice task. 
Appendix Table 4: Non-linear Effects of Liquidity

\begin{tabular}{|c|c|c|c|c|c|c|}
\hline \multirow[b]{3}{*}{ DMA } & \multicolumn{6}{|c|}{ Number of Payday Loans } \\
\hline & (1) & (2) & (3) & (4) & (5) & (6) \\
\hline & $\begin{array}{c}-0.16 \\
(0.06)\end{array}$ & $\begin{array}{c}-0.14 \\
(0.06)\end{array}$ & $\begin{array}{c}-0.14 \\
(0.07)\end{array}$ & $\begin{array}{c}-0.14 \\
(0.07)\end{array}$ & $\begin{array}{c}-0.16 \\
(0.07)\end{array}$ & $\begin{array}{l}-0.15 \\
(0.07)\end{array}$ \\
\hline Liquidity & $\begin{array}{c}-0.47 \\
(0.09)\end{array}$ & $\begin{array}{c}-0.46 \\
(0.08)\end{array}$ & $\begin{array}{l}-0.94 \\
(0.34)\end{array}$ & $\begin{array}{l}-2.02 \\
(0.45)\end{array}$ & $\begin{array}{c}-3.12 \\
(0.78)\end{array}$ & $\begin{array}{l}-3.12 \\
(1.30)\end{array}$ \\
\hline Liquidity $^{2}$ & & $\begin{array}{c}0.09 \\
(0.03)\end{array}$ & & & & \\
\hline Liquidity * Top Half & & & $\begin{array}{c}0.77 \\
(0.37)\end{array}$ & & & \\
\hline Top Half & & & $\begin{array}{c}-3.26 \\
(1.04)\end{array}$ & & & \\
\hline Liquidity * Middle Tercile & & & & $\begin{array}{c}1.64 \\
(0.48)\end{array}$ & & \\
\hline Liquidity * Top Tercile & & & & $\begin{array}{c}1.82 \\
(0.45)\end{array}$ & & \\
\hline Middle Tercile & & & & $\begin{array}{c}-3.44 \\
(1.63)\end{array}$ & & \\
\hline Top Tercile & & & & $\begin{array}{l}-4.51 \\
(1.17)\end{array}$ & & \\
\hline Liquidity * 2nd Quartile & & & & & $\begin{array}{c}3.42 \\
(1.14)\end{array}$ & \\
\hline Liquidity * 3rd Quartile & & & & & $\begin{array}{c}3.00 \\
(0.78)\end{array}$ & \\
\hline Liquidity * Top Quartile & & & & & $\begin{array}{c}2.92 \\
(0.77)\end{array}$ & \\
\hline 2nd Quartile & & & & & $\begin{array}{l}-7.02 \\
(2.98)\end{array}$ & \\
\hline 3rd Quartile & & & & & $\begin{array}{c}-6.15 \\
(1.53)\end{array}$ & \\
\hline Top Quartile & & & & & $\begin{array}{l}-5.61 \\
(1.44)\end{array}$ & \\
\hline Liquidity $* 2$ nd Vintile & & & & & & $\begin{array}{c}3.19 \\
(1.33)\end{array}$ \\
\hline Liquidity * 3rd Vintile & & & & & & $\begin{array}{c}2.56 \\
(1.38)\end{array}$ \\
\hline Liquidity $*$ 4th Vintile & & & & & & $\begin{array}{c}2.99 \\
(1.29)\end{array}$ \\
\hline Liquidity $*$ Top Vintile & & & & & & $\begin{array}{c}2.87 \\
(1.30)\end{array}$ \\
\hline 2nd Vintile & & & & & & $\begin{array}{c}-6.52 \\
(1.81)\end{array}$ \\
\hline 3rd Vintile & & & & & & $\begin{array}{l}-3.45 \\
(3.25)\end{array}$ \\
\hline 4th Vintile & & & & & & $\begin{array}{c}-6.13 \\
(1.72)\end{array}$ \\
\hline Top Vintile & & & & & & $\begin{array}{c}-5.12 \\
(1.84)\end{array}$ \\
\hline $\mathrm{R}^{2}$ & 0.04 & 0.05 & 0.05 & 0.06 & 0.06 & 0.06 \\
\hline
\end{tabular}


Notes: This table investigates whether the effects of liquidity are nonlinear. Decision-making ability, liquidity, and preferences are measured in percentile ranks divided by 10 . The mean of the dependent variable is 0.94 . The regressions include controls for impatience, present bias, risk aversion, log income, years of schooling, gender, age and age squared. Number of observations $=$ 1,573 . 
Appendix Table 5: Alternative Measures of Right-Hand Side Variables

\begin{tabular}{|c|c|c|c|c|c|c|c|c|}
\hline & & & & Num & of Loans & & & \\
\hline & (1) & (2) & (3) & (4) & $(5)$ & (6) & (7) & (8) \\
\hline DMA & $\begin{array}{l}-0.16 \\
(0.07)\end{array}$ & $\begin{array}{l}-0.16 \\
(0.06)\end{array}$ & $\begin{array}{l}-0.14 \\
(0.06)\end{array}$ & $\begin{array}{l}-0.16 \\
(0.07)\end{array}$ & $\begin{array}{l}-0.16 \\
(0.07)\end{array}$ & $\begin{array}{l}-0.19 \\
(0.07)\end{array}$ & $\begin{array}{l}-0.18 \\
(0.07)\end{array}$ & $\begin{array}{l}-0.14 \\
(0.06)\end{array}$ \\
\hline Pctile Rank Liquidity & $\begin{array}{l}-0.47 \\
(0.08)\end{array}$ & $\begin{array}{l}-0.47 \\
(0.09)\end{array}$ & $\begin{array}{l}-0.44 \\
(0.08)\end{array}$ & $\begin{array}{l}-0.41 \\
(0.08)\end{array}$ & $\begin{array}{l}-0.47 \\
(0.09)\end{array}$ & & & $\begin{array}{l}-0.46 \\
(0.08)\end{array}$ \\
\hline Liquidity in $\$ 10,000$ s & & & & & & $\begin{array}{l}-0.26 \\
(0.09)\end{array}$ & & \\
\hline 5th Percentile of Liquidity & & & & & & & $\begin{array}{l}-0.39 \\
(0.21)\end{array}$ & \\
\hline 10th Percentile of Liquidity & & & & & & & $\begin{array}{c}0.03 \\
(0.19)\end{array}$ & \\
\hline 20th Percentile of Liquidity & & & & & & & $\begin{array}{l}-0.18 \\
(0.10)\end{array}$ & \\
\hline Impatience & $\begin{array}{c}0.04 \\
(0.06)\end{array}$ & $\begin{array}{c}0.04 \\
(0.07)\end{array}$ & $\begin{array}{c}0.03 \\
(0.06)\end{array}$ & $\begin{array}{c}0.04 \\
(0.06)\end{array}$ & $\begin{array}{c}0.04 \\
(0.06)\end{array}$ & $\begin{array}{c}0.03 \\
(0.06)\end{array}$ & $\begin{array}{c}0.04 \\
(0.06)\end{array}$ & $\begin{array}{c}0.03 \\
(0.04)\end{array}$ \\
\hline Present Bias & $\begin{array}{c}0.07 \\
(0.07)\end{array}$ & $\begin{array}{c}0.07 \\
(0.07)\end{array}$ & $\begin{array}{c}0.07 \\
(0.07)\end{array}$ & $\begin{array}{c}0.07 \\
(0.07)\end{array}$ & $\begin{array}{c}0.07 \\
(0.07)\end{array}$ & $\begin{array}{c}0.08 \\
(0.07)\end{array}$ & $\begin{array}{c}0.08 \\
(0.07)\end{array}$ & $\begin{array}{c}0.07 \\
(0.07)\end{array}$ \\
\hline $\begin{array}{r}\text { Risk Aversion from Intertemporal } \\
\text { Choice Task }\end{array}$ & $\begin{array}{l}-9.47 \mathrm{E}-05 \\
(0.06)\end{array}$ & $\begin{array}{l}-3.10 \mathrm{E}-03 \\
(0.06)\end{array}$ & $\begin{array}{l}-0.01 \\
(0.06)\end{array}$ & $\begin{array}{l}-0.01 \\
(0.06)\end{array}$ & $\begin{array}{c}1.05 \mathrm{E}-03 \\
(0.06)\end{array}$ & $\begin{array}{c}0.04 \\
(0.07)\end{array}$ & $\begin{array}{c}0.03 \\
(0.07)\end{array}$ & \\
\hline Risk Aversion from Risk Task & & & & & & & & $\begin{array}{c}0.06 \\
(0.05)\end{array}$ \\
\hline Log Income & $\begin{array}{c}0.69 \\
(0.21)\end{array}$ & $\begin{array}{c}0.77 \\
(0.21)\end{array}$ & $\begin{array}{c}0.73 \\
(0.22)\end{array}$ & & & $\begin{array}{c}0.24 \\
(0.18)\end{array}$ & $\begin{array}{c}0.28 \\
(0.18)\end{array}$ & $\begin{array}{c}0.70 \\
(0.21)\end{array}$ \\
\hline Income in $\$ 10,000$ s & & & & $\begin{array}{c}1.13 \mathrm{E}-03 \\
(1.99 \mathrm{E}-03)\end{array}$ & & & & \\
\hline Pctile Rank Income & & & & & $\begin{array}{c}0.19 \\
(0.07)\end{array}$ & & & \\
\hline Years of Schooling & $\begin{array}{l}-0.02 \\
(0.05)\end{array}$ & $\begin{array}{l}-0.01 \\
(0.05)\end{array}$ & & $\begin{array}{l}-0.02 \\
(0.05)\end{array}$ & $\begin{array}{l}-0.02 \\
(0.05)\end{array}$ & $\begin{array}{l}-0.07 \\
(0.05)\end{array}$ & $\begin{array}{l}-0.06 \\
(0.05)\end{array}$ & $\begin{array}{l}-0.02 \\
(0.05)\end{array}$ \\
\hline High School Graduate & & & $\begin{array}{l}-0.95 \\
(1.08)\end{array}$ & & & & & \\
\hline College Degree & & & $\begin{array}{l}-1.91 \\
(0.91)\end{array}$ & & & & & \\
\hline Postgraduate Degree & & & $\begin{array}{l}-1.65 \\
(0.89)\end{array}$ & & & & & \\
\hline Female & $\begin{array}{l}-0.90 \\
(0.37)\end{array}$ & $\begin{array}{l}-0.89 \\
(0.38)\end{array}$ & $\begin{array}{l}-0.78 \\
(0.35)\end{array}$ & $\begin{array}{l}-1.01 \\
(0.39)\end{array}$ & $\begin{array}{l}-0.89 \\
(0.36)\end{array}$ & $\begin{array}{l}-0.82 \\
(0.37)\end{array}$ & $\begin{array}{l}-0.84 \\
(0.37)\end{array}$ & $\begin{array}{l}-0.93 \\
(0.38)\end{array}$ \\
\hline Age & $\begin{array}{c}1.20 \mathrm{E}-03 \\
(0.02)\end{array}$ & & $\begin{array}{c}-2.26 \mathrm{E}-03 \\
(0.02)\end{array}$ & $\begin{array}{c}0.02 \\
(0.02)\end{array}$ & $\begin{array}{c}-1.22 \mathrm{E}-03 \\
(0.02)\end{array}$ & $\begin{array}{l}-0.02 \\
(0.02)\end{array}$ & $\begin{array}{l}-0.01 \\
(0.02)\end{array}$ & $\begin{array}{c}9.21 \mathrm{E}-05 \\
(0.02)\end{array}$ \\
\hline $\mathrm{Age}^{2}$ & $\begin{array}{l}-4.99 \mathrm{E}-04 \\
(4.99 \mathrm{E}-04)\end{array}$ & & $\begin{array}{l}-9.18 \mathrm{E}-04 \\
(6.95 \mathrm{E}-04)\end{array}$ & $\begin{array}{l}-1.39 \mathrm{E}-03 \\
(6.46 \mathrm{E}-04)\end{array}$ & $\begin{array}{l}-4.70 \mathrm{E}-04 \\
(6.76 \mathrm{E}-04)\end{array}$ & $\begin{array}{l}-7.07 \mathrm{E}-04 \\
(6.74 \mathrm{E}-04)\end{array}$ & $\begin{array}{l}-7.28 \mathrm{E}-04 \\
(6.71 \mathrm{E}-04)\end{array}$ & $\begin{array}{c}-5.00 \mathrm{E}-04 \\
(6.56 \mathrm{E}-04)\end{array}$ \\
\hline Age between 35 and 49 & & $\begin{array}{l}-0.35 \\
(0.34)\end{array}$ & & & & & & \\
\hline Age between 50 and 64 & & $\begin{array}{c}0.34 \\
(0.75)\end{array}$ & & & & & & \\
\hline 65 and Older & & $\begin{array}{l}-1.11 \\
(0.46)\end{array}$ & & & & & & \\
\hline $\mathrm{R}^{2}$ & 0.04 & 0.04 & 0.05 & 0.04 & 0.04 & 0.02 & 0.02 & 0.04 \\
\hline
\end{tabular}

Notes: This table investigates the robustness of the results. " $5{ }^{\text {th }}$ Percentile of Liquidity", " $10^{\text {th }}$ Percentile of Liquidity", and " $20^{\text {th }}$

Percentile of Liquidity" were constructed by calculating the within-participant $5^{\text {th }}, 10^{\text {th }}$, and $20^{\text {th }}$ percentiles of liquidity over time. The mean of the dependent variable is 0.94 . Number of observations $=1,573$. 
Appendix Table 6: Measurement Error in Decision-Making Ability

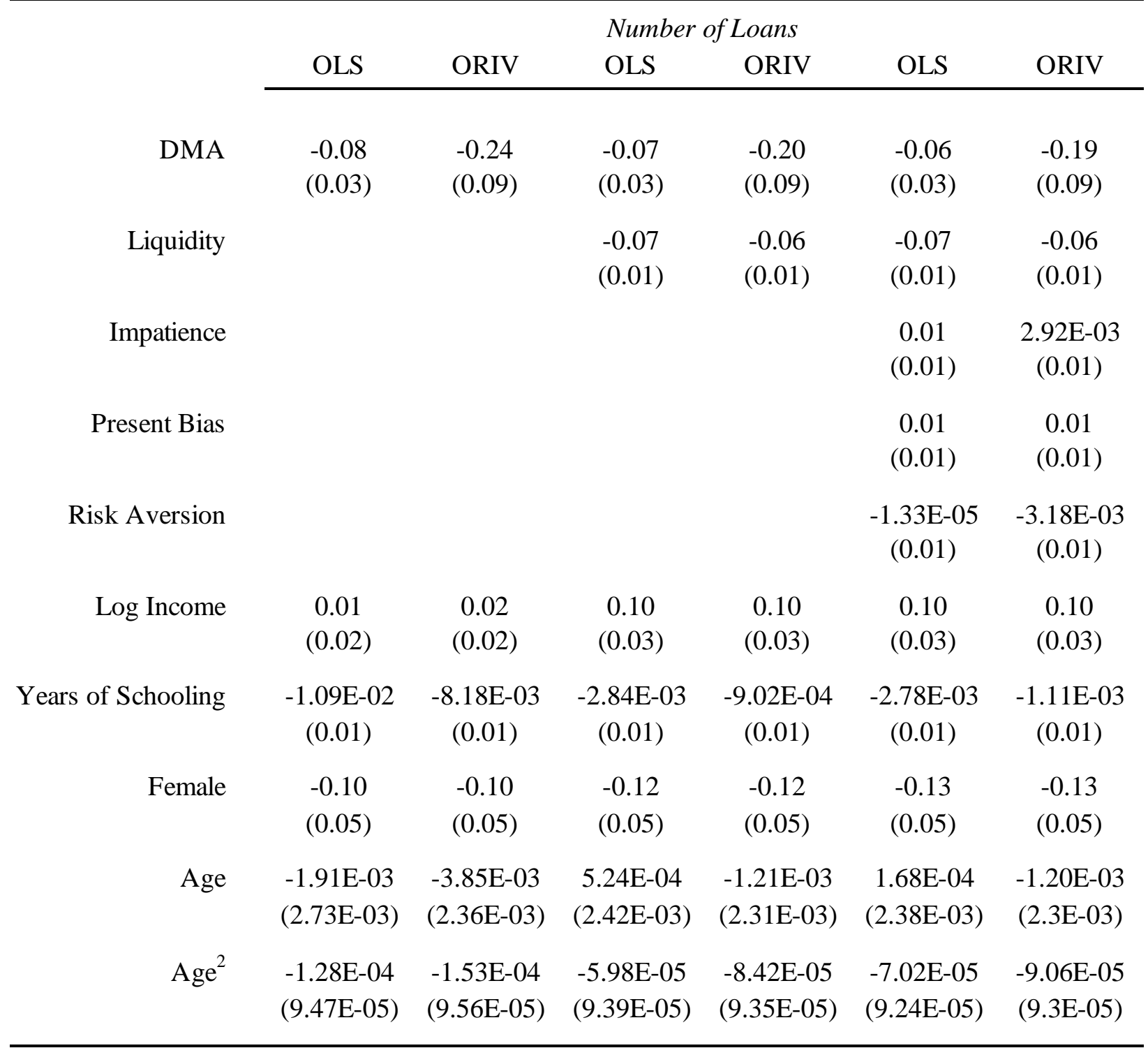

Notes: This table investigates the extent to which measurement in decision-making ability biases the estimates of the relationship between payday loan demand and decision-making ability. ORIV refers to the Obviously Related Instrumental Variables (ORIV) approach (Cf. Gillen et al., 2019). The approach uses DMA derived from the risk task as an instrument for the DMA derived in the ambiguity task while also using the ambiguity DMA to instrument for the risk DMA. The dependent variable and the three measures of decision-making are normalized to have mean zero and variance one. Liquidity and preferences are measured in percentile ranks divided by 10 . Number of observations $=1,573$. 


\section{Appendix Table 7: Decision-making Ability and High-Frequency Variation in Liquidity, Interactive Effects}

\begin{tabular}{|c|c|c|c|c|c|c|}
\hline & \multicolumn{6}{|c|}{1 if Took a Payday Loan } \\
\hline & (1) & $(2)$ & (3) & (4) & $(5)$ & (6) \\
\hline DMA & $\begin{array}{l}-0.88 \\
(0.38)\end{array}$ & $\begin{array}{l}-0.88 \\
(0.38)\end{array}$ & $\begin{array}{l}-0.80 \\
(0.36)\end{array}$ & $\begin{array}{l}-0.83 \\
(0.37)\end{array}$ & $\begin{array}{l}-0.89 \\
(0.38)\end{array}$ & $\begin{array}{l}-0.89 \\
(0.38)\end{array}$ \\
\hline Liquidity in Levels & $\begin{array}{l}-76.47 \\
(24.22)\end{array}$ & $\begin{array}{l}-67.28 \\
(22.38)\end{array}$ & & & & \\
\hline DMA * Liquidity & & $\begin{array}{l}11.28 \\
(7.52)\end{array}$ & & & & \\
\hline IHS of Liquidity & & & $\begin{array}{l}-2.48 \\
(0.66)\end{array}$ & $\begin{array}{l}-2.40 \\
(0.62)\end{array}$ & & \\
\hline DMA * IHS of Liquidity & & & & $\begin{array}{c}0.59 \\
(0.24)\end{array}$ & & \\
\hline PR of Liquidity & & & & & $\begin{array}{l}-0.37 \\
(0.18)\end{array}$ & $\begin{array}{l}-0.37 \\
(0.18)\end{array}$ \\
\hline DMA * PR of Liquidity & & & & & & $\begin{array}{c}0.07 \\
(0.07)\end{array}$ \\
\hline Impatience & $\begin{array}{c}0.03 \\
(0.19)\end{array}$ & $\begin{array}{c}0.03 \\
(0.19)\end{array}$ & $\begin{array}{c}0.03 \\
(0.19)\end{array}$ & $\begin{array}{l}-0.01 \\
(0.19)\end{array}$ & $\begin{array}{c}0.04 \\
(0.19)\end{array}$ & $\begin{array}{c}0.04 \\
(0.19)\end{array}$ \\
\hline Present Bias & $\begin{array}{c}0.52 \\
(0.38)\end{array}$ & $\begin{array}{c}0.52 \\
(0.38)\end{array}$ & $\begin{array}{c}0.48 \\
(0.38)\end{array}$ & $\begin{array}{c}0.48 \\
(0.38)\end{array}$ & $\begin{array}{c}0.53 \\
(0.39)\end{array}$ & $\begin{array}{c}0.53 \\
(0.38)\end{array}$ \\
\hline Risk Aversion & $\begin{array}{c}0.25 \\
(0.30)\end{array}$ & $\begin{array}{c}0.26 \\
(0.30)\end{array}$ & $\begin{array}{c}0.16 \\
(0.30)\end{array}$ & $\begin{array}{c}0.16 \\
(0.30)\end{array}$ & $\begin{array}{c}0.28 \\
(0.30)\end{array}$ & $\begin{array}{c}0.28 \\
(0.30)\end{array}$ \\
\hline Log Income & $\begin{array}{c}1.13 \\
(0.93)\end{array}$ & $\begin{array}{c}1.08 \\
(0.92)\end{array}$ & $\begin{array}{c}2.59 \\
(1.08)\end{array}$ & $\begin{array}{c}2.78 \\
(1.11)\end{array}$ & $\begin{array}{c}0.65 \\
(0.89)\end{array}$ & $\begin{array}{c}0.65 \\
(0.89)\end{array}$ \\
\hline Years of Schooling & $\begin{array}{l}-0.27 \\
(0.20)\end{array}$ & $\begin{array}{l}-0.27 \\
(0.20)\end{array}$ & $\begin{array}{l}-0.09 \\
(0.18)\end{array}$ & $\begin{array}{l}-0.09 \\
(0.18)\end{array}$ & $\begin{array}{l}-0.29 \\
(0.20)\end{array}$ & $\begin{array}{l}-0.29 \\
(0.20)\end{array}$ \\
\hline Female & $\begin{array}{l}-3.66 \\
(2.01)\end{array}$ & $\begin{array}{l}-3.59 \\
(2.00)\end{array}$ & $\begin{array}{l}-3.56 \\
(1.97)\end{array}$ & $\begin{array}{l}-3.17 \\
(1.92)\end{array}$ & $\begin{array}{l}-3.51 \\
(1.99)\end{array}$ & $\begin{array}{l}-3.51 \\
(1.99)\end{array}$ \\
\hline Age & $\begin{array}{l}-0.06 \\
(0.10)\end{array}$ & $\begin{array}{l}-0.06 \\
(0.10)\end{array}$ & $\begin{array}{c}0.00 \\
(0.10)\end{array}$ & $\begin{array}{l}-0.01 \\
(0.10)\end{array}$ & $\begin{array}{l}-0.07 \\
(0.10)\end{array}$ & $\begin{array}{l}-0.07 \\
(0.10)\end{array}$ \\
\hline $\mathrm{Age}^{2}$ & $\begin{array}{l}-4.97 \mathrm{E}-03 \\
(4.19 \mathrm{E}-03)\end{array}$ & $\begin{array}{c}-0.01 \\
(4.19 \mathrm{E}-03)\end{array}$ & $\begin{array}{c}-4.79 \mathrm{E}-03 \\
(4.19 \mathrm{E}-03)\end{array}$ & $\begin{array}{c}-4.37 \mathrm{E}-03 \\
(4.17 \mathrm{E}-03)\end{array}$ & $\begin{array}{c}-0.01 \\
(4.3 \mathrm{E}-03)\end{array}$ & $\begin{array}{c}-0.01 \\
(4.3 \mathrm{E}-03)\end{array}$ \\
\hline $\mathrm{R}^{2}$ & 0.001 & 0.001 & 0.001 & 0.002 & 0.001 & 0.001 \\
\hline
\end{tabular}

Note: This table controls for more flexible forms of liquidity. It shows results from regressions at the individual-daily level. The dependent variable is an indicator for whether participant $i$ took a payday loan on day $d$. We multiplied it by 10,000 so the coefficients can be interpreted as the effect on a hundredth of a percentage point. Its mean is 3.79 . Liquidity refers to the liquidity on the previous day, i.e., $d-1$. Columns (1)-(2) include liquidity in levels as a control. Columns (3)-(4) control for the inverse hyperbolic sine of liquidity. Columns (5)-(6) ads a within-participant percentile rank measure of liquidity. In particular, the liquidity of participant $i$ on day $d-1$ was ranked relative to the liquidity of participant $i$ in all other days in the individual time series of the participant. Decision-making ability, time and risk preferences are measured in percentile ranks divided by 10 , such that the coefficient gives the effect of an increase of 
the independent variable in 10 percentiles. The regressions include dummies for day of the week and for calendar day of the month. Number of observations $=1,388,959$. Number of participants $=1,573$. Number of days $=883$. Standard errors clustered at the individual level. 


\section{Appendix Table 8: Decision-making Ability and Monthly Variation in Liquidity}

\begin{tabular}{|c|c|c|c|c|c|c|}
\hline & & & ber of $L$ & the Month & & \\
\hline & (1) & (2) & (3) & (4) & (5) & (6) \\
\hline DMA & $\begin{array}{l}-0.30 \\
(0.12)\end{array}$ & $\begin{array}{l}-0.30 \\
(0.12)\end{array}$ & $\begin{array}{l}-0.27 \\
(0.12)\end{array}$ & $\begin{array}{l}-0.27 \\
(0.12)\end{array}$ & $\begin{array}{l}-0.24 \\
(0.11)\end{array}$ & $\begin{array}{l}-0.24 \\
(0.11)\end{array}$ \\
\hline Liquidity in Levels & & $\begin{array}{l}-0.26 \\
(0.08)\end{array}$ & $\begin{array}{l}-0.25 \\
(0.08)\end{array}$ & & & \\
\hline Lagged Liquidity in Levels & & & & $\begin{array}{l}-0.24 \\
(0.08)\end{array}$ & & \\
\hline IHS of Liquidity & & & & & $\begin{array}{l}-0.79 \\
(0.21)\end{array}$ & \\
\hline IHS of Lagged Liquidity & & & & & & $\begin{array}{l}-0.74 \\
(0.20)\end{array}$ \\
\hline Impatience & & & $\begin{array}{c}0.01 \\
(0.06)\end{array}$ & $\begin{array}{c}0.01 \\
(0.06)\end{array}$ & $\begin{array}{c}0.01 \\
(0.06)\end{array}$ & $\begin{array}{c}0.01 \\
(0.06)\end{array}$ \\
\hline Present Bias & & & $\begin{array}{c}0.16 \\
(0.12)\end{array}$ & $\begin{array}{c}0.16 \\
(0.12)\end{array}$ & $\begin{array}{c}0.15 \\
(0.11)\end{array}$ & $\begin{array}{c}0.15 \\
(0.11)\end{array}$ \\
\hline Risk Aversion & & & $\begin{array}{c}0.07 \\
(0.09)\end{array}$ & $\begin{array}{c}0.07 \\
(0.09)\end{array}$ & $\begin{array}{c}0.04 \\
(0.09)\end{array}$ & $\begin{array}{c}0.05 \\
(0.09)\end{array}$ \\
\hline Log Income & $\begin{array}{c}0.10 \\
(0.25)\end{array}$ & $\begin{array}{c}0.30 \\
(0.27)\end{array}$ & $\begin{array}{c}0.34 \\
(0.28)\end{array}$ & $\begin{array}{c}0.34 \\
(0.28)\end{array}$ & $\begin{array}{c}0.80 \\
(0.33)\end{array}$ & $\begin{array}{c}0.77 \\
(0.32)\end{array}$ \\
\hline Years of Schooling & $\begin{array}{l}-0.09 \\
(0.06)\end{array}$ & $\begin{array}{l}-0.08 \\
(0.06)\end{array}$ & $\begin{array}{l}-0.08 \\
(0.06)\end{array}$ & $\begin{array}{l}-0.08 \\
(0.06)\end{array}$ & $\begin{array}{l}-0.03 \\
(0.06)\end{array}$ & $\begin{array}{l}-0.03 \\
(0.06)\end{array}$ \\
\hline Female & $\begin{array}{l}-0.92 \\
(0.57)\end{array}$ & $\begin{array}{l}-0.97 \\
(0.58)\end{array}$ & $\begin{array}{l}-1.10 \\
(0.61)\end{array}$ & $\begin{array}{l}-1.10 \\
(0.61)\end{array}$ & $\begin{array}{l}-1.07 \\
(0.60)\end{array}$ & $\begin{array}{l}-1.06 \\
(0.60)\end{array}$ \\
\hline Age & $\begin{array}{l}-0.01 \\
(0.03)\end{array}$ & $\begin{array}{l}-0.01 \\
(0.03)\end{array}$ & $\begin{array}{l}-0.01 \\
(0.03)\end{array}$ & $\begin{array}{l}-0.01 \\
(0.03)\end{array}$ & $\begin{array}{c}2.40 \mathrm{E}-03 \\
(0.03)\end{array}$ & $\begin{array}{c}1.25 \mathrm{E}-03 \\
(0.03)\end{array}$ \\
\hline $\mathrm{Age}^{2}$ & $\begin{array}{c}-1.80 \mathrm{E}-03 \\
(1.3 \mathrm{E}-03)\end{array}$ & $\begin{array}{l}-1.44 \mathrm{E}-03 \\
(1.28 \mathrm{E}-03)\end{array}$ & $\begin{array}{l}-1.61 \mathrm{E}-03 \\
(1.26 \mathrm{E}-03)\end{array}$ & $\begin{array}{l}-1.61 \mathrm{E}-03 \\
(1.26 \mathrm{E}-03)\end{array}$ & $\begin{array}{l}-1.56 \mathrm{E}-03 \\
(1.25 \mathrm{E}-03)\end{array}$ & $\begin{array}{c}-1.59 \mathrm{E}-03 \\
(1.26 \mathrm{E}-03)\end{array}$ \\
\hline $\mathrm{R}^{2}$ & 0.003 & 0.004 & 0.005 & 0.004 & 0.011 & 0.010 \\
\hline
\end{tabular}

Note: This shows results from regressions at the individual-month level. The dependent variable is the number of payday loans participant $i$ took in month $m$. We multiplied it by 100 so the coefficients can be interpreted as the effect in percentage points. Its mean is 1.153 . Liquidity refers to the liquidity on the same month, i.e., $m$. Lagged liquidity refers to the liquidity in the previous month, i.e., $m-1$. Columns (2)-(3) include liquidity in levels as a control. Column (4) controls for lagged liquidity in levels, column (5) for the inverse hyperbolic sine (IHS) of liquidity, and column (6) for the IHS of lagged liquidity. Decision-making ability, time and risk preferences are measured in percentile ranks divided by 10 , such that the coefficient gives the effect of an increase of the independent variable in 
10 percentiles. Number of observations $=44,044$. Number of participants $=1,573$. Number of months $=28$. Standard errors clustered at the individual level. 


\section{Appendix Table 9: Comparison of Survey Sample to Meniga Users}

\begin{tabular}{|c|c|c|c|c|c|}
\hline & \multicolumn{2}{|c|}{ Mean } & \multirow{2}{*}{$\begin{array}{l}\text { P-value Test } \\
\text { Diff in means }\end{array}$} & \multirow[b]{2}{*}{ Frequency } & \multirow{2}{*}{$\begin{array}{l}\text { Number of } \\
\text { Observations }\end{array}$} \\
\hline & Admin & Survey & & & \\
\hline Female & $49 \%$ & $47 \%$ & 0.172 & - & 11,630 \\
\hline Age & 38.8 & 37.4 & $9.29 \mathrm{E}-06$ & - & 11,630 \\
\hline 1 if Took Payday Loan & $0.04 \%$ & $0.04 \%$ & 0.795 & Daily & $25,798,650$ \\
\hline Amount Payday Loan & 0.10 & 0.11 & 0.746 & Daily & $25,798,650$ \\
\hline Income & 6,019 & 5,490 & 0.797 & Monthly & 837,360 \\
\hline Wages & 5,300 & 3,230 & 0.117 & Monthly & 837,360 \\
\hline Checking Balance & 366 & 377 & 0.961 & Daily & $10,432,110$ \\
\hline Savings Balance & 4,340 & 4,386 & 0.922 & Daily & $10,432,110$ \\
\hline Credit Card Balance & 1,735 & 1,823 & 0.467 & Daily & $10,432,110$ \\
\hline Number of NSF Charges & 0.05 & 0.03 & $5.40 \mathrm{E}-05$ & Monthly & 846,856 \\
\hline Cost NSF Charges & 0.36 & 0.28 & 0.002 & Monthly & 846,856 \\
\hline
\end{tabular}

Note: This table compares survey participants $(N=1,573)$ to Meniga users $(N=11,630)$. Both samples are restricted to individuals for whom there are complete data on demographics, payday loans, income, and balances (they may have incomplete data on NSF charges). For the NSF outcomes, the number of individuals are respectively 1,542 and 11,444. The test of difference in means cluster standard errors at the individual level. 
Appendix Table 10: Economic Preferences and Real-Life Outcomes

\begin{tabular}{|c|c|c|c|c|c|c|c|c|c|c|}
\hline & \multicolumn{4}{|c|}{ Rank Percentile of Wealth } & \multicolumn{3}{|c|}{100 if Participates in Stock Market } & \multicolumn{3}{|c|}{ Rank Percentile of Overdraft Balance } \\
\hline & (1) & (2) & (3) & (4) & $(5)$ & $(6)$ & (7) & $(8)$ & (9) & $(10)$ \\
\hline Impatience & $\begin{array}{l}-0.45 \\
(0.19)\end{array}$ & $\begin{array}{l}-0.43 \\
(0.19)\end{array}$ & $\begin{array}{l}-0.15 \\
(0.29)\end{array}$ & $\begin{array}{l}-0.10 \\
(0.29)\end{array}$ & & $\begin{array}{l}-0.09 \\
(0.39)\end{array}$ & $\begin{array}{l}-0.07 \\
(0.39)\end{array}$ & $\begin{array}{c}0.99 \\
(0.20)\end{array}$ & $\begin{array}{c}1.02 \\
(0.32)\end{array}$ & $\begin{array}{c}0.99 \\
(0.32)\end{array}$ \\
\hline Present Bias & & $\begin{array}{l}-0.34 \\
(0.25)\end{array}$ & $\begin{array}{l}-0.25 \\
(0.26)\end{array}$ & $\begin{array}{l}-0.23 \\
(0.26)\end{array}$ & & $\begin{array}{l}-0.26 \\
(0.34)\end{array}$ & $\begin{array}{l}-0.26 \\
(0.34)\end{array}$ & $\begin{array}{c}0.89 \\
(0.28)\end{array}$ & $\begin{array}{c}0.90 \\
(0.29)\end{array}$ & $\begin{array}{c}0.88 \\
(0.29)\end{array}$ \\
\hline DMA & & & & $\begin{array}{c}0.64 \\
(0.26)\end{array}$ & & & $\begin{array}{c}0.19 \\
(0.36)\end{array}$ & & & $\begin{array}{l}-0.32 \\
(0.29)\end{array}$ \\
\hline Log Income & $\begin{array}{c}8.57 \\
(1.39)\end{array}$ & $\begin{array}{c}8.51 \\
(1.39)\end{array}$ & $\begin{array}{c}8.42 \\
(1.38)\end{array}$ & $\begin{array}{c}8.29 \\
(1.36)\end{array}$ & $\begin{array}{c}4.93 \\
(1.58)\end{array}$ & $\begin{array}{c}4.91 \\
(1.58)\end{array}$ & $\begin{array}{c}4.87 \\
(1.58)\end{array}$ & $\begin{array}{c}2.16 \\
(1.15)\end{array}$ & $\begin{array}{c}2.15 \\
(1.15)\end{array}$ & $\begin{array}{c}2.21 \\
(1.15)\end{array}$ \\
\hline Female & $\begin{array}{l}-6.94 \\
(1.45)\end{array}$ & $\begin{array}{l}-6.78 \\
(1.45)\end{array}$ & $\begin{array}{l}-6.68 \\
(1.45)\end{array}$ & $\begin{array}{l}-6.63 \\
(1.45)\end{array}$ & $\begin{array}{l}-11.27 \\
(1.98)\end{array}$ & $\begin{array}{l}-11.17 \\
(1.98)\end{array}$ & $\begin{array}{l}-11.16 \\
(1.98)\end{array}$ & $\begin{array}{c}1.88 \\
(1.57)\end{array}$ & $\begin{array}{c}1.89 \\
(1.58)\end{array}$ & $\begin{array}{c}1.87 \\
(1.58)\end{array}$ \\
\hline Age & $\begin{array}{c}0.35 \\
(0.08)\end{array}$ & $\begin{array}{c}0.35 \\
(0.08)\end{array}$ & $\begin{array}{c}0.37 \\
(0.08)\end{array}$ & $\begin{array}{c}0.39 \\
(0.08)\end{array}$ & $\begin{array}{c}0.13 \\
(0.10)\end{array}$ & $\begin{array}{c}0.13 \\
(0.10)\end{array}$ & $\begin{array}{c}0.13 \\
(0.11)\end{array}$ & $\begin{array}{c}0.34 \\
(0.08)\end{array}$ & $\begin{array}{c}0.34 \\
(0.08)\end{array}$ & $\begin{array}{c}0.33 \\
(0.08)\end{array}$ \\
\hline $\mathrm{Age}^{2}$ & $\begin{array}{l}-7.41 \mathrm{E}-03 \\
(5.06 \mathrm{E}-03)\end{array}$ & $\begin{array}{l}-7.14 \mathrm{E}-03 \\
(5.04 \mathrm{E}-03)\end{array}$ & $\begin{array}{l}-0.01 \\
(0.01)\end{array}$ & $\begin{array}{l}-0.01 \\
(0.01)\end{array}$ & $\begin{array}{c}0.01 \\
(0.01)\end{array}$ & $\begin{array}{c}0.01 \\
(0.01)\end{array}$ & $\begin{array}{c}0.01 \\
(0.01)\end{array}$ & $\begin{array}{c}-0.03 \\
(4.28 \mathrm{E}-03)\end{array}$ & $\begin{array}{c}-0.03 \\
(4.28 \mathrm{E}-03)\end{array}$ & $\begin{array}{c}-0.03 \\
(4.27 \mathrm{E}-03)\end{array}$ \\
\hline $\begin{array}{c}\text { Number of Obs } \\
\text { Mean of Y }\end{array}$ & $\begin{array}{l}1,547 \\
48.90\end{array}$ & $\begin{array}{l}1,547 \\
48.90\end{array}$ & $\begin{array}{l}1,547 \\
48.90\end{array}$ & $\begin{array}{l}1,547 \\
48.90\end{array}$ & $\begin{array}{l}1,557 \\
18.88\end{array}$ & $\begin{array}{l}1,557 \\
18.88\end{array}$ & $\begin{array}{l}1,557 \\
18.88\end{array}$ & $\begin{array}{c}1,410,981 \\
27.98\end{array}$ & $\begin{array}{c}1,410,981 \\
27.98\end{array}$ & $\begin{array}{c}1,410,981 \\
27.98\end{array}$ \\
\hline
\end{tabular}

Note: This table investigates whether the experimental measures of economic preferences predicted real-life outcomes that have been documented by previous work (Epper et al. 2018; Barsky et al. 1997; Meier \& Sprenger 2010). Data on wealth and stock market participation come from the survey. Participants reported the value of different types of assets, including stocks. Information about 
overdraft balances come from the administrative data. In columns (8)-(10), standard errors clustered at the individual level. Robust standard errors in all other columns. 
Appendix Table 11: Summary Statistics of Non-sufficient Funds Charges

\begin{tabular}{|c|c|c|c|c|c|c|}
\hline & \multirow[b]{2}{*}{ Mean } & \multicolumn{5}{|c|}{ Percentiles } \\
\hline & & 10th & 25 th & 50th & 75th & 90th \\
\hline \multicolumn{7}{|l|}{ Individual-Month } \\
\hline Total Cost of Charges & 15.48 & 7.50 & 7.51 & 9.05 & 18.00 & 43.30 \\
\hline Number of Charges & 1.8 & 1 & 1 & 1 & 2 & 5 \\
\hline \multicolumn{7}{|l|}{ Over Entire Period } \\
\hline Total Cost of Charges & 79.47 & 7.51 & 9.53 & 37.54 & 96.89 & 312.06 \\
\hline Number of Charges & 9.3 & 1 & 2 & 5 & 11 & 36 \\
\hline
\end{tabular}

